\title{
Longitudinal studies of human growth and health A review of recent historical research
}

\author{
July 2010 \\ Kris Inwood \\ Department of Economics and Department of History \\ University of Guelph \\ kinwood@uoguelph.ca \\ Evan Roberts \\ Department of History and Minnesota Population Center, University of Minnesota \\ History Programme, Victoria University of Wellington \\ eroberts@umn.edu
}

Forthcoming in Journal of Economic Surveys, 24(4), November 2010

\begin{abstract}
This paper reviews recent literature using stature and weight as measures of human welfare with a particular interest in cliometric or historical research. We begin with an overview of anthropometric evidence of living standards and the new but fastgrowing field of anthropometric history. This literature is always implicitly and often explicitly longitudinal in nature. We then discuss (i) systematic empirical research into the relationship between conditions in early life and later life health and mortality and (ii) historical evidence on the relationship between body mass, morbidity and mortality. We conclude with a discussion of the importance of historical sources and understandings to health economics and population health.
\end{abstract}

Keywords: Physical stature; Height; Obesity; Well-being; Anthropometric history; Biological standard of living JEL codes: I120, J110, N300, N310, N320, N330, O150 


\subsection{Introduction}

Understanding change in individual circumstances and behavior across time is a key objective of research in many fields of economics, including economic history. Given a proper sampling method, inferences about changing circumstances can be made using independent samples of different individuals at different points in time, or cross-sectional data. Reliable inference about changes in behavior and circumstance often requires repeated observations on the same individuals across time, or longitudinal data. Longitudinal data, although not a panacea for every inferential issue, allow researchers to disentangle individual- and period-specific effects in background and behavior. In this paper we review the literature in economic history and portions of closely related fields such as demographic and medical history that uses longitudinal data on human stature, weight and health to explain trends and determinants of living standards.

We discuss the following issues in the paper. First, we review the rationale for using stature and weight as measures of human welfare. The questions in this literature are at least implicitly, and often explicitly, longitudinal. We then discuss empirical research into the relationship between conditions in early life, and later life health and mortality. Because height is a summary measure of nutritional conditions in the first two decades of life, studies of the relationship between height and health use the latter to proxy for early life conditions. A related literature—-largely but not entirely from epidemiology—seeks to understand the relationship between conditions in utero—often measured by birth weight—and health in later life (Barker, 1998). These areas of research revolve around the influence of environmental conditions on later health that are exogenous to the individual. Babies have no influence over their conditions in the womb, and children have very limited influence over 
factors that affect their net nutrition and attained height. Conversely, adult body weight may be appropriately thought of as a rational choice dependent on preferences, technology and relative prices (Philipson and Posner, 2003; Lakdawalla and Philipson, 2009; Lumey, Stein et al., 2010 forthcoming). Beyond a certain point increases in body mass are undesirable for humans, bringing an increased risk of morbidity, particularly cardiovascular conditions, and consequently increased risk of mortality (Gillman, 2004). The outstanding research question that we review in this paper is if the relationship among body mass, morbidity, and mortality has changed between historical and contemporary populations. Although as yet relatively few historical articles address this question, the first results suggest that the relationship between body mass and mortality has changed somewhat between nineteenth century and modern populations. To ground our discussion of longitudinal studies, we begin with an overview of anthropometric evidence of living standards and the new but fast-growing field of anthropometric history.

2.0 Anthropometric measures of living standards

Anthropometric research infers living standards and health from measures of height and body mass. An interest in historical sources and in the long-term and historical experience of height and weight has grown substantially in the last thirty years, in part because anthropometric measures of welfare complement standard economic measures of welfare such as earnings or income. Anthropometric measures are helpful for historical and contemporary populations when reliable income data are not available, as in most countries before the early twentieth century, and in many developing countries today (Moradi and Baten, 2005; Heltberg, 2009). Reliable statistics on earnings or income are available only from the mid-nineteenth century for many countries, whereas anthropometric data can be 
found for some populations in the eighteenth century and earlier. The use of skeletal remains allows the measurement of heights and welfare for much earlier periods (Steckel and Rose, 2002; Steckel, 2005). Moreover, the use of alternative dimensions of living standards such as anthropometric measures or life expectancy is warranted by the expectation that monetary measures of income are not sufficient, and that human welfare is multi-dimensional (Fleurbaey, 2009). Even when reliable income data are available, the use of anthropometric measures may allow greater insight into inequality between sub-populations in the same country or region. Anthropometric research relies heavily on microdata that record individual characteristics such as height and weight. In the military and judicial records that are common sources for anthropometric history, socio-economic information such as occupation, literacy and ethnicity are also often available. This allows anthropometric analysts to calculate differences in mean stature or body mass by socio-economic groups or other subcomponents of a population giving insights into the long-term evolution of inequality between groups.

The anthropometric approach to measuring living standards takes a net nutrition perspective on human welfare. The two common measures used in anthropometric research are height and body mass, or body weight normalized for height. The common abbreviation for body mass, which we will use, is BMI. Adult height or terminal height is the product of both genetic and environmental influences (Silventoinen, 2003; McEvoy and Visscher, 2009). Genetic variation clearly accounts for much of the variation in stature within any population, and yet changes over several decades and differences between socio-economic groups in the average stature largely reflect environmental influences (Tanner, 1981; Faulkner and Tanner, 1986; Eveleth and Tanner, 1990; Bogin, 1999b). Between birth and the early twenties a human body has the capability to grow in stature. The most rapid periods of growth are from 
birth to three years, and in early adolescence. Males normally continue growing for longer than females, so that in well-nourished populations without significant gender inequality males are, on average, 11.5 to $12.5 \mathrm{~cm}$, taller than females. Three-quarters of the gender difference arises because boys grow for 2 more years at pre-adolescent rates (i.e. their growth spurt is delayed); boys also have a slightly larger growth spurt (higher amplitude and modestly greater length). But the body only puts energy taken in through food to the purpose of growth after fueling immediate mental and physical activities, and fighting disease. Thus the human potential for growth in stature can be compromised in three principal ways, which while conceptually separate, are not mutually exclusive. First, food intake may be restricted because food is in short supply, such as in a war or famine, or the relative price of food groups important to growth increases. Protein, especially milk protein, is particularly important for growth in human stature (Bogin, 1999b). Second, disease can retard growth by diverting energy to fighting disease, or causing inadequate absorption of the nutrients consumed. Finally, increases in the intensity or volume of physical activity without compensating increases in caloric intake also decrease the calories available for growth (Steckel, 2008). Conversely, the potential for stature growth will be enhanced if nutrient-rich food becomes more readily available or cheaper, disease incidence falls, or the physical intensity of daily activities decreases.

The net nutrition perspective that uses terminal stature as a measure of welfare is implicitly longitudinal since adult stature reflects the cumulative influence of environmental and economic patterns during the lengthy human growth period. Compared to other mammals, and even other primates, the human growth period is long in absolute length and compared to the potential lifespan (Leigh and Park, 1998; Bogin, 1999a; Leigh, 2001). Humans typically have two periods of rapid growth in stature; an infant growth spurt from birth to 
approximately 3 years, and an adolescent growth spurt that begins after 11 years of age. While the conclusion of the infant growth phase is relatively uniform between individuals, the timing of the onset and length of the adolescent growth spurt differs considerably between individuals and is subject to both genetic and environmental influences. A constant genetic difference is that females normally begin their adolescent growth spurt two years earlier than males. In well-nourished populations the adolescent growth spurt has begun earlier for both sexes, and concluded earlier, reflective of environmental influences. Human stature is most likely to be compromised from its genetic potential during the two growth spurts of infancy and adolescence. Correspondingly changes in population stature for a birth cohort sharing a similar nutritional environment—-such as being born and residing in the same region or country—will largely reflect net nutrition in infancy and adolescence. Decreases in average stature point to periods of decreased welfare from declining food consumption or increases in workload or disease, which are taken to be economic "bads."

Because height is a summary measure of net nutrition over 20 years anthropometric studies of previous populations share a common inferential problem. Adult height and birth cohort alone identify a span of 20 years in which environmental influences might have changed growth relative to previous cohorts. Within that span of 20 years there are two especially critical growth periods—infancy and adolescence—which researchers must examine for potential environmental changes that might have affected growth. To further complicate inference, the human growth cycle is flexible. Poor nutrition at an early age can be partially overcome with a compensating growth spurt later (Steckel, 1986). In severely malnourished populations the attainment of terminal height can be delayed until the mid-20s (Bogin, 1999b). Thus, identifying changes in the average stature of a population does not identify the timing or cause of the change because the typical anthropometric study observes individual 
heights just once—in adulthood—but there are multiple years and multiple causes for a single change in height. These inferential issues do not invalidate the large and growing literature that uses height as a measure of human welfare, but do point to the desirability of longitudinal data that observes individuals at two or more points in time (Steckel, 2009b). While we concentrate in this review on what can be learned from longitudinal data, and emphasize their inferential advantages anthropometric historians have other options. Synthetic longitudinal data can be constructed from large cross-sectional studies of children (Steckel, 2009a). Aggregated data on correlates of net nutrition such as disease load, prices, and environmental conditions have been used to good effect by anthropometric historians to identify the timing of nutritional changes affecting particular cohorts.

\subsection{Anthropometric history}

Since the early uses of anthropometric evidence in economics during the 1970s much effort has been devoted to establishing trends in population stature and body mass across different countries, explaining periods of change in average stature, and identifying periods of change still requiring full explanation due to the inferential problems just mentioned. We summarize some important findings in this literature and provide an illustrative example to set our discussion of the longitudinal research in anthropometric history in context. Readers desiring a more complete discussion of the evolution of this research area should consult the insightful review articles by Steckel (Steckel, 1995; Steckel, 1998; Steckel, 2009b). The use by economists and economic historians of anthropometric evidence- biological indicators that reflect the living standards of past populations_-owes a considerable debt to human biologists (Tanner 1978; 1981). A seminal contribution in modern historical anthropometric research was the Steckel and Trussel use of growth velocities to demonstrate that the average 
age at menarche for American slaves was about 15. Because slave women did not bear their first child until an average age of 20.6 years, this finding implies that slaves were not bearing children as soon as they were physiologically capable (Trussel and Steckel, 1978). Steckel, Robert Fogel, Stanley Engerman and others initiated a stream of research that began to figure prominently in major journals and in the National Bureau of Economic Research's new Development of the American Economy (Engerman, 1976; Steckel, 1979; Fogel, Engerman et al., 1982; Engerman, 2004). Much of the early research in anthropometric history examined the United States and western-European experience, but since the mid-1990s the scope of this rapidly-growing research has widened to include literally every settled continent. Because the American and European literature is of longer standing there is greater agreement about the trends in stature in these areas.

The most significant stylized fact to emerge from the anthropometric history literature is that North America and much of western Europe experienced a period of stagnating or diminishing stature during some portion of the nineteenth century. This finding provides an important qualification to the otherwise consistent evidence of improvements in the material standard of living during the nineteenth century (Komlos, 1998; Haines, 2004). The bestknown experience of this phenomenon is the so-called antebellum puzzle in the United States (Komlos, 1987). The physical stature of successive cohorts of students entering the West Point military academy declined in spite of rapid economic growth before the Civil War. In a broad sense the potential causes of the decline in stature-reduced calories relative to physical requirements for daily activities and fighting disease-are agreed upon, but in this case as in others it has proven challenging to identify with precision the relative importance of different influences (Gallman, 1996; Komlos, 1996; Coelho and McGuire, 2000; Steckel, 2000). The inferential problems discussed above mean that assessing the relative 
contribution of diet, disease and workload to changes in stature is demanding of both data and method (Haines, Craig et al., 2003). Of course, the problem is complicated further because the relative contribution of these factors is likely to differ across cohorts and countries.

\subsection{Diet}

Before the advent of refrigerated transportation, proximity to nutrients was associated with being taller. People living in rural areas, and especially those living on farms themselves, were likely to be taller. Refrigerated transport and reduced transportation costs from the development of the railroad network reduced the rural height advantage around the turn of the twentieth century (Craig, Goodwin et al., 2004). Milk because of its high protein:calorie ratio is important to human growth (Bogin, 1999b; Baten and Murray, 2000). The availability of fresh milk contributed to the rural height advantage. Economic historians have emphasized the role of relative price shifts in nutritional choices, and the variance of food prices for different population groups, such as urban and rural residents. Anthropometric research has shown that while urban and industrial growth did not lead to dramatic immiseration or starvation, it could contribute to reduced consumption at the margin. Even relatively small decreases in average food consumption could affect population stature if the changes were concentrated in lower income groups (Komlos, 1998).

\subsection{Disease}

Rural height advantages in the nineteenth century from diet were complemented by an advantage from lower rates of disease than urban areas (Haines, 2001; Haines, 2004). The urban penalty was not universal, with urban men in Belgium being taller than their rural peers (Alter, Neven et al., 2004). Improved public health and food distribution saw the elimination 
of the urban height penalty in the United States by the mid-twentieth century although exactly when the urban penalty disappeared in different environments is not clearly known and probably varied (Steckel, 1995). The importance accorded to disease exposure in the anthropometric literature in populations before the modern health transition appears to be increasing.

\subsection{Work intensity}

Industrial work and urban living contributed to declines in average stature, because industrial labor remained physically demanding. The calorie requirements of industrial workers were not greatly different from those of agricultural laborers (Komlos, 1996). However it was recognized at the time that industrial workers were more likely to be malnourished relative to their work effort. Indeed, there was contemporary research into the food consumption and energy requirements of urban industrial workers (Oddy, 1970; Aronson, 1982). It was not until the turn of the twentieth century with the growing substitution of mechanical for human power in industrial work and the growth of white-collar work, that average daily calorie requirements in work decreased significantly (Komlos and Ritschl, 1995; Voth, 1996). The importance of work intensity for stature change in nineteenth century North America and Western Europe is not known to be large relative to the effects of diet and disease, although admittedly this may simply reflect the limited availability of evidence about individual-level variation in the demands of work.

\subsection{Inequality}

Anthropometric history has also shown inequality in societies for which few reliable surveys of money earnings or income survive. In the United States inequality in heights was most pronounced in the nineteenth century. Professionals and farmers were taller than clerical and 
skilled trades workers, with urban laborers being shortest on average (Steckel and Haurin, 1995). Similar degrees of inequality in height are evident in Canada, Australia and New Zealand, with the range between the tallest professionals or farmers and unskilled laborers being less than 5cm (Whitwell and Nicholas, 2001; Cranfield and Inwood, 2007; Inwood, Oxley et al., 2010 forthcoming). Inequality in stature was greater in Europe. For example, in England the mean stature of 14 year old boys at the elite Sandhurst school was $10-15 \mathrm{~cm}$ greater than orphans (Floud, Wachter et al., 1990).

\subsection{Gender}

An interest in inequality also motivates studies of the difference between male and female heights. Stature is an important and easily measurable aspect of sexual dimorphism or differences in body composition. The differences mainly emerge at puberty; at birth males are only $1 \%$ longer than females, but in adulthood men are, on average, $7 \%$ taller (Gaulin and Boster, 1985; Gustafsson and Lindenfors, 2004). The difference is primarily due to men having greater leg length in part because their pubertal period is longer than women's. Men also have a higher fat-free mass and a lower body fat percentage for a given weight. Sexual dimorphism in shape diminishes at advanced ages; both sexes tend to lose lean mass after age 40, so that even individuals with a stable weight have a higher body fat percentage as they age (Wells, 2007).

The magnitude of the sexual difference in stature and body mass varies between societies, and is susceptible to environmental, social and economic influences. Thus differences in size dimorphism may reflect differences in net nutrition between the sexes from which, in turn, we may infer patterns of intra-household resource allocation that would otherwise remain hidden. Variation in the degree of dimorphism has been observed in pre-historic populations 
studied as well as modern groups (Frayer and Wolpoff, 1985). Since genetic variation occurs very slowly (Rogers and Mukherjee, 1992) changes in stature dimorphism are likely to reflect sex-specific changes in environment and living standards (Gustafsson, Werdelin et al., 2007). The cause of variation in societal dimorphism continues to be debated by scholars in anthropology and biology (Eveleth, 1975; Gray and Wolfe, 1980; Holden and Mace, 1999; Nettle, 2002; Gustafsson and Lindenfors, 2004; Kanazawa and Novak, 2004; Gustafsson, Werdelin et al., 2007).

Disagreement continues for several reasons. The magnitude of dimorphism is relatively small, and the samples used to measure it, particularly in prehistoric populations, are also quite small. Analyses seek to explain variation in the ratio of male:female stature within a range of roughly 1.04 to 1.12 (Gray and Wolfe, 1980). Explanatory influences are themselves difficult to measure in pre-historic populations. While not widely discussed in the anthropological and biological literature, differing selection in samples even from the same time and place can influence measure of stature by sex and thus the apparent extent of dimorphism.

A critical question is whether or not the sexes respond similarly to nutritional conditions. The conventional conclusion is that "the growth of boys, from prenatal life to adulthood, appears to be more 'sensitive' to environmental factors than the growth of girls" (Bogin, 1999b). Although widely accepted in the anthropometric literature this hypothesis deserves further scrutiny, for two reasons. First, it follows from boys' growth being more sensitive to environmental conditions that sexual stature dimorphism should increase as stature itself grows. However, a recent study from Sweden using similar data sources for men and women found no increase in dimorphism over the twentieth century (Gustafsson, Werdelin et al., 
2007). Second, because stature in both sexes at a point in time is strongly influenced by socio-economic status the degree of dimorphism will be influenced by selection into and composition of the sample. Average stature in both sexes can plausibly vary by $2-3 \mathrm{~cm}$ from the true population average if, for example, the sample is dominated by unusually tall (farmers) or short (urban workers) groups. Biases of this magnitude at plausible values of average stature will make the ratio of male:female stature different enough from the true value (1.05 vs 1.07$)$ that observed changes in the ratio could be the result of changing sample selection rather than true variation.

Historical research on women's stature and body mass is limited by the availability of systematic sources before the late twentieth century. Women appear in military and prison records less frequently and in a less representative way than men. Women in the military, for example, have tended to be nurses who represent a more highly selective group from all women than soldiers were from all men. Military nursing on a large scale dates from World War I, and yet already by World War II the selection changed as the number of nurses increased and women began to serve in a broader range of auxiliary military roles. Similarly the selection of women into prisons was different than for men. In Europe, North America and Australasia, women were (and are) imprisoned less often than men and for a narrower range of offences. Concerns about differential sample selection between the sexes are somewhat relaxed in the twentieth century because researchers have access to more systematic collection of data on children's heights in schools and, after World War II, population anthropometric surveys of adults. The shift from highly selective to representative sampling of women obscures the long-run trend in dimorphism. 
Studies of female stature in Britain and Ireland, and among American slaves have been particularly important. After 1807 slaves in the United States were measured when shipped between ports; they comprise one of the few historical populations where a male and female sample was selected on the same principles. Steckel has used the slave manifests to show that both male and female slaves' growth was retarded in childhood, but caught up dramatically in adolescence. Nutrition was relatively poor for both sexes (Steckel, 1986).

Studies of the height of British and Irish prisoners from the nineteenth century illustrate the potential for using anthropometric measures to identify gender inequality. Oxley and Nicholas report a smaller gap between rural and urban stature in early nineteenth century Ireland than in England among female prisoners (Nicholas and Oxley, 1993). They argue that rural stature fell more rapidly for rural English women because their labor market opportunities deteriorated, reducing the returns from investing in growth and causing girls to receive less food than their brothers whose labor market prospects were better. Such interpretations of height decline are difficult to confirm from other sources although nonetheless it is agreed that adult women had poorer net nutrition than men because of labor market considerations (Floud, 1998; Harris, 2009). For example, in mid-nineteenth century Britain incarcerated women have been found to be $0.8 \mathrm{~kg} / \mathrm{m}^{2}$ lighter than men of the same age. On the same basic prison diet, $60 \%$ of women in prison gained weight while $70 \%$ of men lost weight (Horrell, Meredith et al., 2007; Horrell, Meredith et al., 2009).

There is also evidence of a long-run trend towards greater sexual dimorphism in heights from India (Brennan, Macdonald et al., 1994; Deaton, 2008; Viswanathan and Sharma, 2009). The Indian research spanning more than a century has necessarily combined selective documentary evidence from the past, with more representative modern survey data. The 
latter have minimal selection issues between men and women. But the historical data, manifests of indentured laborers leaving India, are more complex because the selection of men and women into the pool of indentured laborers may have differed. Brennan et al argue that the selection effect understates an estimated height decline and, strengthens the conclusion of growing dimorphism. Here, as in the other studies, the most important insight from research on men's and women's anthropometry is likely to be the connection between labor market returns and claims on nutritional resources in the household.

3.7 An example of anthropometric research from cross-sections of the population The British prison data follow men and women through time but more commonly anthropometric researches relies on a cross-sectional source from which some longitudinal influence may be inferred. A useful example is provided by preliminary results from a project examining the evolution of physical stature in New Zealand (Inwood, Oxley et al., 2009; Inwood, Oxley et al., 2010 forthcoming). This analysis illustrates what can be learned as well as the limits of knowledge from conventional anthropometric research. A multivariate estimation on the first round of data from this project describe 4939 soldiers who were born in New Zealand and served in the army during World War Two is reported in Table One. The truncated maximum likelihood regression model accommodates evidence that soldiers less than 64 inches tall may be under-represented.

[Insert Table One about here]

Inequality within the population is evidenced by the report in Table One that men from the professional and clerical class were six-tenths of an inch taller than labourers (the omitted occupational category in the regression are skilled tradespeople). These data, in themselves, 
cannot tell us if the working class disadvantage reflects poorer diet, more demanding working conditions or the disease burden of less healthy living and working conditions. The twotenths of an inch height advantage of farm labourer over other labourers undoubtedly reflects the fact that the relative price of food was lower on the farm and that the lower population density of rural residents provided some protection from infectious disease. The estimation provides no way to disentangle the relative importance of the food price and disease exposure effects. Farmers were a full inch taller than non-farm labourers; presumably this reflects the combined influence of more limited disease exposure and greater wealth. Soldiers who enlisted with a name that was recognizably Māori (the indigenous population of New Zealand) were half an inch shorter than urban labourers. Mortality and morbidity among the Māori is known to have been disastrous in this period so it is not surprising to find that they were shorter as well (Pool, 1991). Again, however, we do not yet know the relative importance of nutrition, disease and work intensity to the loss of Māori stature relative to non-Māori New Zealanders.

The same regression framework allows us to say if New Zealanders were becoming shorter or taller over time. Somewhat surprisingly, in view of the experience of health improvement in many other countries at this time, successive birth cohorts of New Zealanders were not becoming taller after the turn of the century. There is no statistically significant difference in height between the reference group (men born 1910-1914) and any other birth group.

Anthropometric studies of this sort are not directly longitudinal in the sense of collecting evidence of well-being at different points in a life. Rather adult health is interpreted with reference to information about the person's early life experience (birthplace, birth year, etc). Thus early-life environmental (broadly-defined) influences can be seen to influence later-life 
health. Most anthropometric studies are implicitly longitudinal in this sense. In most cases the evidence of earlier-life conditions such as birth location and date is collected at the time of measuring stature. The limitations of this process arise in part from the potentially confounding effects of survivor bias and also from the inaccuracy of human recall (Batty, Lawlor et al., 2005; Kauhanen, Lakka et al., 2006; Haas, 2007; Murphy, 2009). Many people know their age and birthplace more or less precisely with some variation in precision by inter alia education, social class, and migration status. More complex detail and information about other family members is likely to be correspondingly less imprecise.

An important and growing class of studies is able to obtain direct evidence of health at multiple points in a person's life. A number of studies attempt to correlate adult health experience with stresses received in utero. Research examining the children born in the aftermath of the Dutch winter famine of 1944 has been particularly influential (Lumey and Van Poppel, 1994; Lumey, 1998). The Dutch winter famine studies contribute to the extensive and varied, although still contested, evidence for the implications of fetal environment for adult health in the shape of risk for major chronic diseases, such as cardiovascular disease, stroke, hypertension, Type 2 diabetes, and obesity; the best-known contributions are those of Barker (Barker, 1992; Barker, 1998; Barker, 2004). A large and growing literature investigates the 'natural experiment' consequences of severe famines for long-term health of survivors and even their descendents (Lumey, Stein et al., 2010 forthcoming).

Another kind of anthropometric study that obtains direct evidence of health early and late in life is based on children who were examined medically in the early and middle decades of the twentieth century and then subsequently followed through to identify the adult and later life 
experience of health. For example, the Boyd Orr sample collected a great deal of diet and health information about 4999 children in 1937-1939 Scotland and England (Martin, Gunnell et al., 2005). Fifty years later another set of researchers retrieved the original records, located the children's National Health Records and thereby acquired long-term longitudinal data with rich detail about health and its determinants for children and again in later life. The Boyd Orr longitudinal data have supported a wide range of studies including, recently, analyses of the significant impact of early life conditions on adult stature and later-life health (Frijters, Hatton et al., 2010; Hatton and Martin, 2010). A number of other early twentieth century sources, many of them administrative in nature, have been matched to later life information to constitute new longitudinal data (Hart, Taylor et al., 2004; Starr, Taylor et al., 2004; Lawlor, Martin et al., 2006; Batty, Shipley et al., 2009).

The inter-war Boyd Orr study was paralleled by the initiation of several longitudinal studies in the United States, some of which continued to the present day. Then, as now, the interest in longitudinal studies was interdisciplinary, with medicine, education and psychology to the fore. Particularly important were the Oakland Growth Study (1920-21 birth cohort) that interviewed children and their families four times in the 1930s, and returned to them in the 1950s and 1972. The Berkeley Growth and Guidance studied a cohort born in 1929 from infancy. Similar longitudinal studies were started in Colorado, Iowa, Minnesota, Ohio, and Massachusetts (Wall and Williams, 1970; Sontag, 1971; Mednick and Mednick, 1984; Young, Savola et al., 1991). Somewhat atheoretical in their design and with relatively small sample sizes, these early longitudinal studies collected anthropometric information that makes them useful for subsequent research (Tanner, 1981; Himes, 2006). 
In the post-war era European governments launch a number studies designed from the outset to support life-course studies of human growth and health. A Medical Research Council Study begun in 1948, for example, collected information about British children born two years earlier. These children were later resampled at intervals to obtain true longitudinal data that have been used in a wide variety of studies (Wadsworth, Kuh et al., 2006). Additional longitudinal studies were launched in Britain and in western Europe during the 1950s and 1960s (Leon, Lawlor et al., 2006; Power and Elliott, 2006; Stenberg and Vagero, 2006; Osler, Godtfredsen et al., 2008). Some sources such as the 1946 cohort study begin following the subjects in early life, while others such as the Whitehall studies begin tracking people as adults and also reach backwards with the ex-post addition of early-life information (Batty, Shipley et al., 2009). In the United States a large number of longitudinal projects were begun from the 1950s through 1970s. The US National Collaborative Perinatal Project study and Oakland Child Health and Development Study that contain birth cohorts from 1959-1967 have been followed up extensively for growth and health outcomes (van den Berg, Christianson et al., 1988; Hardy, 2003; Mei, Grummer-Strawn et al., 2004; Klebanoff, 2009). The variety of sources and database design implies that historians of the second half of the twentieth century have at their disposal a diversity of sources supporting longitudinal anthropometric analysis although, admittedly, coverage varies by country and becomes more complete over time. Longitudinal sources offer the very considerable advantage over crosssectional evidence that individual differences, for example, in onset of the growth spurt, which may be the focus of interest, do not disappear into cross-sectional averaging.

The limitation to this genre of analysis arises from the timing of the medical exam and the age at which people were examined. Very few if any research studies of health and physical well-being that follow individuals through time or provide personal identifiers allowing 
longitudinal reconstruction pre-date the Boyd Orr sample. Research on child health during the early $20^{\text {th }}$ century was extensively reported and is invaluable for historical analysis, but it provides limited evidence about cohorts born in the nineteenth century (Harris, 1995). Hospital birth records allow the construction of longitudinal data but few records are available to document births before the mid-nineteenth century (Ward, 1993; McCalman, Morley et al., 2008). The First World War military entrance exams such as those reported above support analysis of physical well-being and linkage to other sources for people born in the 1860 s, but no earlier. Thus the construction of longitudinal data from prison, hospital, military and other administrative sources usefully extends back into the nineteenth century the populations and cohorts for which the relationship between body composition and health can be examined over the life course.

Cohorts born before the 1920s can only be studied longitudinally by linking diverse original sources. In this respect anthropometric research parallels the methods used to examine occupational and geographic mobility. Historical mobility studies in the 1960s and 1970s relied on hand searches and often were restricted to linking people who had not moved far from their original residence (Thernstrom, 1964). The development of complete machinereadable indices to population registers and censuses removed the restriction. Joseph Ferrie's 1996 book Yankeys Now pioneered the genre by tracing 2595 immigrants across the United States from 1850 to 1860 using census indices (Ferrie, 1999). More recently systematic data mining techniques and inexpensive computing has permitted a generalization and expansion of Ferrie-type longitudinal data (Goeken, 2010 forthcoming). In order to construct these data we need original sources describing the population at different times with similar identification variables such as name, race, birth date and location (and in some cases characteristics of parents). To connect together different original sources the researcher 
matches individual characteristics that do not change over time (or change predictably, for example age). It may be difficult to match individuals with widely shared characteristics (e.g. the surname of Smith) because there are so many potential matches in the different record sources. In practice the decision about matching individuals is inexact and probabilistic because of variations in the way names were recorded, age heaping, and errors in the original enumeration and transcribing the handwritten sources into a machine-readable format.

4.0 The relationship between body composition, morbidity and mortality

Determining if the relationship between body composition and health has changed is critical to using nutritional measures of living standards over time. Studies of living standards using anthropometric measures interpret increases in average height and body mass as indicative of higher real wages (due to lower food costs), lower disease incidence, or reduced physical intensity of work. In the absence of other changes to welfare these improvements to net nutrition can be interpreted as improvements to living standards. However, if the relationship between body composition and health changes, then changes in body composition over time cannot be interpreted as pure improvements in living standards.

To make the issue more concrete, consider the hypothesis that improvements in medical technology might lower the mortality risks of obesity. There are two separate, but not mutually exclusive, ways in which the obesity-mortality relationship might have changed. First, the obesity-mortality function could shift, giving a lower mortality risk at any given BMI. Second, the shape of the obesity-health function could change, lowering the mortality risk of an increase in BMI. We emphasize that these are hypotheses about possible changes, 
rather than established results, which we discuss later. If the obesity-health relationship has shifted, then the implicit price of obesity has changed. People are able to have their cake and eat it too. Conversely, an unchanging relationship between obesity and health across cohorts and countries is powerful evidence that the obesity-health relationship approximates a biological constant. If the obesity-health relationship is stable across time and place, we can compare changes in the population distribution of body composition among diverse populations, and forecast the implications of changing body composition. Conversely, if the obesity-health relationship has shifted substantially over just a century there is evidence that the obesity-health relationship is mediated by social and economic factors. Thus a key question for historical longitudinal studies in anthropometric history is whether the heighthealth and body mass-health relationship has changed substantially over time.

In this section we discuss historical and modern evidence on the relationship between height and weight, and morbidity and mortality. Weight and height direct our attention at different points in human life as critical in determining morbidity and mortality. While studies of height and health in later life address the relationship of early-life experience and later-life health, studies of weight and health seek to address the question of how behavior in adulthood—closer to the end of the lifespan — affect morbidity and mortality. The two perspectives are not opposed. Morbidity and mortality risk can be affected by both growth period experiences, and adult experiences and behavior. Yet the emphasis on early-life or adult experience as the primary cause of disease and mortality has shifted over the twentieth century (Kuh and Smith, 1993). Prior to World War II researchers from a variety of disciplines emphasized the early-life antecedents of adult disease and mortality. However, in the 1950s and 1960s there was a much greater influence on adult behavior-such as poor nutrition manifesting in overweight — as a primary cause of morbidity (Kuh and Ben-Shlomo, 
2004). Interest in early life influences—often summarized by height in historical studies_resumed in the 1970s. The current epidemiological consensus is that morbidity and mortality risk are determined over the life span. Moreover, the relative contributions of early life and adult experiences and behavior are likely to differ between individuals and between morbidities. The data requirements to answer this form of question are high. Conclusions are thus necessarily partial and inclusive—both early and later life experiences affect morbidity and mortality.

\subsection{Height and health}

The ultimate question in studies of the relationship between height and health is the longterm relationship between the cumulative effect of childhood - or growth periodexperiences and health in later life. Height in itself is not the variable of interest. Rather, height summarizes influences across the growth period. Particularly in retrospective or historical data, it may be one of the few reliable variables about early life experience available. In retrospective data collection, where respondents are asked about events occurring several decades earlier, recall of significant health events is likely to be biased or inaccurate (Coughlin, 1990; Friedenreich, 1994). Occupational and residential information is remembered quite accurately over 50 years, but childhood health is recalled less accurately (Berney and Blane, 1997; Batty, Lawlor et al., 2005). Nevertheless, for living cohorts there are methods such as life-grid interviews that provide usable data on major life course events that may affect later health (Blane, Berney et al., 1999; Holland, Berney et al., 2000).

Collecting new data is not an option for cohorts that are dead. While there are surviving early twentieth century medical and social surveys that include health information and can be usefully re-examined by economic historians (Hatton and Martin, 2010), examining the 
relationship between early life (growth period) conditions and later life health requires height data for any studies of the nineteenth century and much of the early twentieth century. The medical literature on how life course influences shape morbidity and mortality particularly emphasize the importance for future research of obtaining information on the growth trajectory, and knowing more than attained adult height (Ben-Shlomo and Kuh, 2004). Economic historians might usefully try to uncover sources such as school health records that could provide more information on childhood growth trajectories.

\subsubsection{Height and morbidity}

A significant amount of modern research on the association between height and morbidity has focused on the relationship between height and coronary heart disease. Across the population height has been shown to be inversely associated with the development of cardiovascular diseases. In other words, shorter people have a higher risk of developing cardiovascular diseases. Similarly, there is an inverse association between height and diabetes, with shorter men having a higher prevalence of diabetes, and greater levels of insulin resistance. Modern researchers who have been able to collect data on the components of height have found a stronger correlation between leg length and adult cardiovascular disease than total height. This correlation is significant because more of environmental variation in height comes through variation in leg length than in torso length. That is, people who are shorter than their genetic potential due to deprivation in childhood tend to be shorter in the legs than they could have been (Elford and Ben-Shlomo, 2004; Lawlor, Ben-Shlomo et al., 2004). The conclusion from modern research is that the inverse relationship between height and cardiovascular disease is most likely due to cardiovascular disease being a longterm consequence of conditions in childhood that are also reflected in height. Height has also 
been shown to be inversely related to stroke, respiratory disease, and stomach cancers, and that the association is due to early life conditions manifesting in both reduced stature and disease (Davey Smith and Lynch, 2004). However, height is not associated with the development of hypertension (Whincup, Cook et al., 2004). The emerging and important literature examining long-term consequences of famine for children will add further evidence (Lumey, Stein et al., 2010 forthcoming). Already it seems clear that chronic malnutrition or repeated famine has much more serious impact than a single episode of food deprivation.

\subsubsection{Height and mortality}

The relationship between height and mortality addresses indirectly the question of whether conditions in early life—reflected in height—also affect survival in the long run. The mechanisms for how early life conditions affect mortality and life expectancy are unclear in much of this research, opening up further questions rather than resolving issues.

Waaler's pioneering research with 1.7 million Norwegians demonstrated that height was associated with increased longevity in late-adult men, and that the effects were substantial (Waaler, 1984). Among men aged 55-59 at initial screening and followed for 17 years, the mortality of men standing $185-189 \mathrm{~cm}$ was half that of men $150-55 \mathrm{~cm}$. However, while the relative risk for shorter men appeared dramatic, the population at risk was very small. Less than eight percent of the population studied had an excess mortality risk of more than $50 \%$. A subsequent follow-up of the same population for another 17 years to the year 2000, maintained Waaler's basic results. Men shorter than $165 \mathrm{~cm}$ had an elevated mortality risk, but above that height there was no increase in the risk of death over 25-34 years of follow-up (Engeland, Bjorge et al., 2003). British researchers have found similar results in smaller 
samples. Height was inversely associated with all cause, coronary heart disease, stroke, and respiratory disease mortality in a 20 year study of Scottish men (Davey Smith, Hart et al., 2000). Similarly using data from the Whitehall study of British civil servants, an increase in height of $15 \mathrm{~cm}$ was associated with a $10 \%$ reduction in mortality risk (Batty, Shipley et al., 2006; Batty, Shipley et al., 2009). A Finnish study showed even stronger support for the relationship with a $5 \mathrm{~cm}$ increase in height being associated with $10 \%$ declines in mortality risk (Jousilahti, Tuomilehto et al., 2000). Recent papers using Asian and Australasian data from prospective medical studies found that a $6 \mathrm{~cm}$ (1 standard deviation) increase in height was associated with a $3 \%$ decline in mortality risk. This finding is significant because of the extension to non-European ethnic groups. No significant differences were found between the Asian and Australasian populations, suggesting this relationship is robust across different ethnic groups (Song, Smith et al., 2003; Lee, Barzi et al., 2009). Moreover, studies of identical twins have demonstrated that the shorter twin had an increased chance of coronary heart disease mortality (Silventoinen, Zdravkovic et al., 2006). In summary, the direction of the association between short stature and increased mortality risk is well established in modern research. The estimated size of the relationship varies across countries. This would be surprising if the association was a biological one with little variation, but the risk of short stature is likely to vary across countries and time depending on social and economic conditions. Estimating how the relationship has changed and why remains a challenge for economic historians.

The extensive modern research is complemented by just two historical studies addressing the same question directly. Engaging directly with Waaler's results Costa examined the mortality risk of stature in a sample of Union Army veterans (Costa, 1993). Her findings broadly paralleled the modern research. Mortality risk declined with increasing height after 
$160 \mathrm{~cm}$ and was lowest from 183 to $188 \mathrm{~cm}$. Mortality risk began to rise again for very tall men. Subsequent research by Murray on the mortality risk of stature in a sample of elite Amherst college students complicates the historical picture (Murray, 1997). Murray found no relation between height and mortality risk. He concluded that the influence of height on mortality was mediated by social and behavioral factors. In economically homogeneous groups, such as elite college students in the nineteenth century United States height may not be predictive of mortality. In an economically homogeneous sample the variation in height is likely to be more genetic than reflective of environmental and economic conditions in childhood. Despite Murray's null finding, the similarity of the relationship in Costa's research with the extensive modern evidence suggests the height-mortality relationship is not unchanging, but certainly long-standing. Additional research on historical populations is necessary to show how the strength of the relationship has changed across time and space.

\subsection{Weight and health}

Longitudinal studies involving weight are even more tightly constrained than studies of height by limitations on the availability and quality of evidence. Before the nineteenth century there was not adequate technology to accurately record human weights. While balance scales—-such as the steelyard—have been used since ancient times they are of little value for measuring live weight (which moves). Fairbanks scales were perfected and mass produced in the United States by the middle of the 19th century, and were more stable and suitable for weighing people and animals. By the mid-1870s Fairbanks scales and similar designs manufactured elsewhere were used in anthropometric studies (Bowditch, 1877; Roberts, 1879). Ironically the weight of platform scales, which were too bulky and expensive to have been used in the field and at muster stations, means we have little historical data on 
weight before the late nineteenth century.

Both historical and modern research show that individuals at the extremes of the weight distribution have a higher risk of mortality, with the risks mediated through specific diseases. Here we consider men only since anthropometric historical data on a longitudinal basis for women are scarce. Indeed, even modern medical studies have paid less attention to these issues for women (Kuh and Hardy, 2004). Although the mortality risk of being overweight dominates the academic and policy discussion today, being underweight was a more common health risk in before World War II.

The greater prevalence of underweight adults before World War II was related to the three contributors to net nutrition discussed above, namely caloric intake, disease burden, and physical intensity of daily living. Humans today, particularly in industrial and service work but also in agriculture, expend substantially less energy in work and transport activities than they did a century ago (Cutler, Glaeser et al., 2003; Philipson and Posner, 2003). People in the past needed more calories just to carry out their daily activities. Moreover, nutritious food was expensive relative to income, both to acquire and prepare (Logan, 2006; Logan, 2009). Mass urbanization in the nineteenth century reduced the ability of western populations to produce their own food supplies that they could consume if they were unemployed or had reduced wages. Finally common infectious gastrointestinal and respiratory diseases led to weight loss, and were associated with significant (but declining) mortality in the nineteenth century and first half of the twentieth century. Thus, despite the current policy and academic concern about overweight as a risk factor for morbidity and mortality, historical studies also show an important relationship between being underweight and later mortality. 


\subsubsection{Weight and morbidity}

Mortality — when not caused by accidents or suicide — is a consequence of specific illnesses. The relationship between BMI and specific morbidities mediates the relationship between BMI and mortality. Technological change in health care has changed the mortality risk of different morbidities over time, and the population prevalence of different morbidities has also changed. The changing mortality risk of BMI can be seen as the product of changes in these two terms. First there is the risk of contracting specific morbidities conditional on BMI, and second a risk of dying due to that morbidity in a given time period. As well as the risk of developing chronic diseases related to obesity, there is also evidence that the strain from obesity on the muscular-skeletal system may contribute to back and joint problems, and arthritis (Felson, 1996; Ferraro, Su et al., 2002; Symmons, Bankhead et al., 2005). Modern health surveys in the United States, Europe and Australasia have also documented that selfrated health declines with increasing weight (Must, Spadano et al., 1999; Sturm and Wells, 2001; Jia and Lubetkin, 2005; Sach, Barton et al., 2006).

Modern health research in developed countries on the relationship between weight and morbidity focuses nearly entirely on the relationship between excess weight and morbidity. While there are substantial health consequences of malnutrition, and these remain a serious health concern in developing countries, in high income industrialized nations a concern with the health consequences of being overweight has grown over the twentieth century (Czerniawski, 2007). Excess weight and obesity are associated primarily with a range of chronic conditions affecting the circulatory and metabolic systems. In particular the link between being overweight and coronary heart disease has been a focus of medical research since immediately after World War II (Keys, Aravanis et al., 1972; Kuh and Smith, 1993). 
More recently the link between obesity throughout the life course, and the development of diabetes, has received significant attention (Forouhi, Hall et al., 2004). Obesity in adulthood also contributes significantly to high blood pressure, a condition that can be a precursor to cerebrovascular conditions (stroke) and coronary heart disease (Whincup, Cook et al., 2004). Overweight and obesity is also related to the development of site-specific cancers. Among men overweight and obesity is associated with a greater risk of kidney and stomach cancer (Davey Smith, Sterne et al., 2009).

Historical evidence on the relationship between weight and morbidity is limited to two recent papers using the Union Army dataset that is central to research in this field (Costa, 1996; Johansen, 2000; Linares and Su, 2005). Unfortunately the data required for understanding non-fatal sickness or morbidity estimates in historical populations is unlikely to exist for many populations. It is possible to study the relationship between body composition and mortality with observations at just two points in time. For example, soldiers who were weighed and measured upon enlistment can be linked to their single death certificate. Moreover, people die just once, and the event is well-defined and thus well-recorded in many societies. Conceptual and causal issues remain because the etiology of how BMI at, say, age 18 influences mortality risk at age 50 is not entirely clear. Nevertheless, the data required to estimate a relationship can be generated from reasonably representative and available sources with well-understood selection criteria. Conversely, people fall sick frequently and the definition of being "sick" changes over time (Riley, 1990; Johansson, 2004). Moreover, people whose illnesses were recorded in, for example, friendly society or benefit fund records, may have been more likely to be sick-a common moral hazard problem in health insurance (Murray, 2007). Particularly in the past when medical care for many conditions was ineffective or counterproductive, and relatively expensive, most people did not present to 
a doctor for treatment. For the nineteenth century the available sources to study morbidity at an individual level are limited. American Civil War veterans from the Union Army and members of sickness benefit societies are possible sources (Gorsky, Harris et al., 2006).

Although primarily asking how health affected labor supply, Costa's 1996 study of 597 men from the Union Army dataset also showed the effect of BMI on specific health conditions affecting labor force participation (Costa, 1996). Costa found that the relationship between BMI and non-participation in the labor market was "remarkably similar" in 1900 and the late twentieth century. Non-participation was least likely at a BMI of 25, and increased at lower and higher BMI values. However, in the early twentieth century men were more responsive to changes in BMI. Costa also found that the relationship between BMI and specific diseases had changed. Whereas in modern populations heart disease risk increases with BMI, in the early twentieth century heart disease and BMI were negatively related. In a relatively small sample, however, Costa was not able to discriminate between specific morbidities.

Using an expanded version of the Union Army dataset with 5600 men, Linares and Su (2005) were able to consider the relationship between BMI and four common chronic disease groups: cardiovascular, gastrointestinal, respiratory, and rheumatism/musculoskeletal. Linares and Su's analysis examined the relationship of BMI with both the number of disease groups veterans contracted, and the occurrence of specific individual conditions. Although health guidelines define normal weight as a BMI between 20 and 25, Linares and Su found that the number of chronic diseases suffered by veterans was minimized at a BMI of 27 , or slightly overweight by modern standards. Thus, the relationship between BMI and chronic conditions was U-shaped. Underweight and overweight were both associated with suffering 
more chronic disease. Moreover, the average BMI in the Union Army dataset was 23.3, so most veterans had a greater than optimal number of chronic conditions.

When examining specific conditions, Linares and Su found a similar U-shaped relationship between BMI and the occurrence of cardiovascular, gastrointestinal and respiratory diseases. The curvilinear relationship was strongest for cardiovascular diseases. The risk of having a cardiovascular illness was nearly $50 \%$ greater for men with a BMI of 35 compared with men near the optimum BMI at 27. Similarly, extremely underweight men also had a much greater risk of cardiovascular disease. The pattern for gastrointestinal and respiratory diseases was slightly different: men with a BMI below had a much greater risk of suffering these diseases than men at the optimum BMI of 27. The increased risk of gastrointestinal and respiratory disease was minimal for obese men, compared with men around the optimum weight. In contrast to the common U-shaped pattern, rheumatism and musculoskeletal diseases increased linearly with BMI. Although morbidity was related to BMI in the cross-section, Linares and $\mathrm{Su}$ found that weight change between medical examinations only affected the chance of gastrointestinal diseases. Men who had gained weight between examinations were significantly less likely to have contracted a gastrointestinal disease. It is critical to note the causality of this finding runs from the specific disease group to body mass. Gastrointestinal diseases are often associated with weight loss because of difficulty retaining food that has been consumed, rather than weight gain having a biologically protective effect against gastrointestinal disease. Conversely, while Linares and Su did not find strong evidence for it in their historical cohort, in modern studies there is both a statistical association and a causal physiological relationship between weight gain and cardiovascular disease (Rosengren, Wedel et al., 1999; Wannamethee, Shaper et al., 2005). 
The small economic history literature on the relationship between BMI and specific morbidities comes exclusively from research using the Union Army dataset. Thus, the results discussed above are not truly independent of each other. Unsurprisingly they point to similar results. However, the research using Union Army data is consistent with modern research. People at the extremes of the body mass distribution have a higher risk of contracting specific morbidities. The morbidity risks of being underweight were more common in historical populations. The issues of significant overweight and obesity were not unknown to historical populations, but less common than in contemporary cohorts. Limited data availability accounts for the dearth of historical research on the relationship between body mass and morbidity. Thus, opportunities for further research in this area are likely to be limited. Finding sources and assembling data from diverse historical records will remain the greatest challenge.

\subsubsection{Weight and mortality}

The recognition that individuals at the extremes of the body mass distribution have a higher risk of mortality has been widely accepted in medical research and practice throughout the twentieth century. Moreover, it is established that the mortality risk of excess weight is specific to circulatory diseases, some cancers, and diabetes. What is less clear is when in the life course excess weight is a particular risk. In the 1950s and 1960s when cardiovascular disease mortality in industrialized nations became an increasingly common cause of death, medical and epidemiological research emphasized excess weight in mid-adulthood as the most important risk factor. Since the 1970s, and particularly in the last two decades, medical and epidemiological research has paid increasing attention to other periods in the life course. Medical research has shown some mortality risk from excess weight in childhood (even if 
later BMI values are normal), and from fluctuations in adult weight that increase mortality risk even if an individual is in a normal BMI range much of the time (Kuh and Smith, 1993).

The inspiration for much of the economic history literature on the relationship between body composition and mortality was a large-scale Norwegian study (Waaler, 1984). Height and weight were measured between 1963 and 1975 as part of a tuberculosis screening program, and deaths of the same individuals traced from 1963 to 1979. Waaler's research showed that the U-shaped relationship between body mass and mortality flattened as the age of initial measurement increased. All individuals measured at age 85 have a high risk of dying in the next 17 years, so the relative mortality risk for extremely slender or obese people is lower. Conversely, for individuals in their 20s and 30s the risk of mortality in the next 17 years is low, and people with extreme BMI values have a high relative risk of dying. With an extremely large sample Waaler was able to show that the U-shaped relationship between mortality and body mass was also found after stratifying by height. Taller men with moderate BMI values had the lowest mortality risk. Again, taking advantage of the extremely large sample Waaler was able to show that the U-shaped relationship was strongest for particular diseases. Cerebrovascular (stroke) disease showed a strong U-shaped relationship with body mass, while cardiovascular diseases and diabetes had weaker U-shaped relationships. The excess mortality risk of being obese was greatest for stroke and diabetes.

Waaler's results have been supported by many subsequent studies. The most robust result is the substantial increase in mortality risk for obese $(\mathrm{BMI} \geq 30)$ individuals in mid and lateadulthood (30-64). The relative risk of mortality for obese men has generally been found to be at least $50 \%$ greater than the mortality risk for men with a BMI between 20 and 25 . For example Calle and colleagues in a prospective study of more than a million United States 
residents over 14 years of follow-up found that 30-64 year old men with a BMI of 32-35 had an all-cause mortality risk 2.17 times higher than men whose BMI was between 23.5 and 25 (Calle, Thun et al., 1999). Calle and colleagues found that smoking substantially modified the relationship between low BMI and mortality. Amongst non-smokers with no pre-existing major diseases, the relationship between BMI and mortality risk was J-shaped. Risk rose only slightly for very lean men (BMI below 20). A U-shaped relationship was found for smokers, both with and without a history of other diseases. Because of the significant smoking rates in industrialized countries from approximately World War I to the 1980s, the association between leanness and mortality is confounded by smoking behavior (Pierce, 1989; Giskes, Kunst et al., 2005; Preston and Wang, 2006). In populations with very low smoking prevalence, such as Seventh Day Adventists who abstained from smoking for religious reasons, a positive linear relationship has been found between BMI and mortality risk (Lindsted, Tonstad et al., 1991). Similar results have been found in other studies that controlled for smoking history in measuring the relationship between body mass and mortality (Lee, Manson et al., 1993; Solomon and Manson, 1997; Singh, Lindsted et al., 1999; Allison, Zhu et al., 2002). These studies typically showed that there was no adverse effect of a BMI as low as 19. The implications for historical anthropometric research are most profound in studying cohorts who were in adulthood during the twentieth century. The growing availability of anthropometric data from the two world wars in the twentieth century mean that increasing research will be done on these populations. It is unlikely that the available data sources for these historical populations will be able to control for smoking behavior since what is typically available to researchers from military records are anthropometric measures in young adulthood, medical records from later in life, and death records. For cohorts living mainly through the nineteenth century when smoking prevalence 
was much lower the confounding effect of smoking on the BMI-mortality relationship is less of an issue.

A further issue raised by modern studies is when in the life course mortality risk is raised by excess weight. For example, a study by Hoffmans of Dutch men born in 1932, measured in 1950 for military service and followed for 32 years, found that the relative mortality risk of men overweight at 18 rose "slightly" after 15 years, and "steeply" after 20 years of follow-up (Hoffmans, Kromhout et al., 1988; Hoffmans, Kromhout et al., 1989). People can live with excess weight for several decades in childhood and early adulthood, but the risk rises over time. Because of the recent development of research interest in the links between childhood through early adult BMI and health in later life, many studies do not yet have enough deaths to test for a relationship between BMI and mortality. Thus, alternative endpoints such as the development of particular diseases are chosen. For example, there is no relationship between excess BMI in early childhood (3-6 years) and coronary heart disease in later life. However BMI in later childhood (7-18 years) and early adulthood (18-30) was positively related to later development of coronary heart disease (Owen, Whincup et al., 2009).

A frequent finding in the epidemiological literature is that the relative mortality risk of being obese diminishes in the very elderly. In an older sample everyone has a high risk of dying, so the relative risk of being obese falls (Corrada, Kawas et al., 2006). However, the difference in mortality rates between the obese and the lean may widen in older samples. For example, Stevens found that over 11 years of follow-up 1.5\% of men aged 30-39 with a BMI between 18.5 and 25 died, compared to $3.6 \%$ of obese men. Among men aged $60-69$ the mortality rates were $25.3 \%$ and $31.9 \%$ respectively (Stevens, 2000). A related question to the mortality differences between groups is a comparison of the years of life lost in different BMI 
categories. Stevens found that on average the years of life lost for the obese was less than a year more than in the normal weight category. While obesity carries health risks and raises relative mortality, the years of life lost due to obesity may be relatively modest. Recent work by Mehta and Chang advances this argument further (Mehta and Chang, 2009). Using data from the United States Health and Retirement Study, which studied individuals born between 1931 and 1941 from 1992 to 2004, they found the mortality risk of obesity only rose significantly for BMI levels above 35. People with a BMI between 30 and 34-who have been found to have a significantly higher relative risk of mortality in many previous studies-had a mortality risk similar to people in the normal weight and overweight categories. Mehta and Chang attributed just 3\% of observed male mortality to obesity, compared to $50 \%$ attributable to smoking. However, Mehta and Chang's conclusions are challenged by other recent research that forecast the life expectancy costs of obesity in the United States to rise (Stewart, Cutler et al., 2009).

The limited number of historical studies of the relationship between weight, or body mass index (BMI), and mortality confirm the findings of modern research that extreme body mass values have a greater mortality risk. Historical research shows that mortality risk for men in their fifties and sixties is lowest at a BMI between 20 and 27. World Health Organisation guidelines for healthy weight currently define BMI values of 18.5-25 as a healthy weight (World Health Organization, 1999). However there is emerging evidence from large-scale epidemiological research that the increased mortality risk of having a BMI between 25 and 30 — categorized as overweight by WHO and other public health agencies—-may be diminishing (McGee and Diverse Population Collaboration, 2005). The development of medical devices and pharmaceuticals to treat cardiovascular and related conditions may have reduced the cost of being slightly overweight. The mortality risks of obesity (BMI between 
30 and 35) and severe obesity (BMI over 35) remain high. The proportion of the population classified as overweight or obese has been growing in most countries since the 1970s. The mortality risks of being obese do not appear to have changed substantially in the past century, but the population at risk has increased substantially. However, there is evidence that the risks of being moderately overweight have decreased through the twentieth century.

The only historical studies of the relationship between weight and mortality for cohorts born in the nineteenth century come from the United States. With the exception of John Murray's 1997 article on Amherst College students, the Union Army data provide the sole source of evidence on this topic (Fogel, 1993; Murray, 1997). Historical research on the relationship between weight and mortality has explicitly aimed to produce results comparable with modern studies. From the first article measuring the BMI-mortality relationship in an historical population, researchers have aimed to make comparisons with the contemporary literature (Costa, 1993). Comparisons with Waaler's pioneering 1984 study of Norwegian men have been particularly important in the historical literature (Waaler, 1984).

Costa and subsequent authors have drawn on datasets created of men who served in the Union Army during the American Civil War, and were born in the first half of the nineteenth century, when mean stature of American men was declining - a phenomenon known as the antebellum puzzle (Haines, Craig et al., 2003). Using an early version of the Union Army dataset Costa was able to study the relationship between BMI and mortality for 377 men who were weighed between the ages of 45 and 49 as part of pension exams (Costa, 1993).

Compared to modern populations, the Union Army veterans were light, with an average BMI of 22.8 compared to a BMI of 25 among the Norwegian men measured in Waaler's research (Waaler, 1984). Over a 25-year follow-up period the risk of mortality was lowest for men 
with a BMI between 21 and 28. With a small sample Costa was not able to examine the risk of BMI for specific causes of death, but found that the relationship between weight and mortality was the same when men described as "very sick" were not included in the estimation. Costa concluded that the shape of the BMI-mortality relationship was the same in historical and modern populations, and that the location was similar with BMI risk lowest between 21 and 28. Using the same sample Costa also found that reduced stature was associated with higher mortality. With both stature and BMI rising in modern populations, the question is which effect dominates? Over the past century in the United States, at a population level the effects of increases in stature, reflecting better net-nutrition in childhood, have dominated the effects of increased BMI (Fogel and Costa, 1997).

Subsequent research with an expanded Union Army dataset has modified, but not overturned Costa's conclusions. The U-shaped relationship between weight and mortality remains, but the slope of the curve has changed. Costa began with a sample of 1447 men, and the analysis of BMI and mortality risk included just 322 men. Recent research with the Union Army data has used samples of up to 10,000 men depending on sample restrictions, and compared the results to modern health surveys. For example, Henderson was able to use a sample of 9,509 Union Army veterans examined after 1865 (Henderson, 2005). Henderson compared the Union Army cohorts born before 1845 with men in the first wave of the National Health and Nutrition Examination Surveys (NHANES I) carried out between 1971 and 1975. Henderson also found that the relationship between BMI and mortality was U-shaped and reached a minimum for men with a BMI between 20 and 30 in both cohorts. With greater sample size, Henderson was able to make finer conclusions on changes in the shape and location of the BMI-mortality curve. Henderson found that the relative mortality risk of extreme BMI values—both underweight and obese—was smaller in the nineteenth century. The overall 
BMI-mortality curve was flatter for the Union Army cohort. In the Union Army cohorts men with a BMI of 30-35 were approximately $26 \%$ more likely to die within 20 years of examination. In the NHANES I samples, men in the same BMI range were 49-60\% more likely to die within 20 years of examination. Similarly, the mortality risk of having a BMI under 20 was greater in the twentieth century cohorts. Yet Henderson also found that moderately overweight men with a BMI of between 25 and 30 had reduced mortality risk in the twentieth century. Henderson concludes that twentieth century cohorts had higher fat-free mass for the same BMI-equivalent to a lower body fat percentage-increasing the chances of survival at BMI values in the normal and moderately overweight range (20-30).

Other authors have confirmed Henderson's conclusion that fat-free mass at a given BMI has increased since the nineteenth century (Costa, 2004; $\mathrm{Su}, 2005)$. Su compared a sample of 1238 men from the Union Army dataset followed up over 18 years, with a sample of 861 from the NHANES follow-up sample. The incidence of obesity increased from $2.5 \%$ amongst the Union Army cohorts in 1890 to $28 \%$ in the NHANES sample measured in the early 1970s. Su found that in the Union Army cohorts underweight men had the greatest risk of death over 18 years, compared to men who were overweight. The difference was greatest in the first 9 years after follow-up-with a $20 \%$ difference in survival rates between underweight men and their heavier peers. But after 18 years the survival gap between BMI categories had narrowed significantly to just $12 \%$. More of the underweight men died soon after their initial examination because some were already suffering from gastrointestinal diseases. While the same order of mortality risks was found in the NHANES cohorts, the mortality risks diverged over time. In the first 9 years the gap between the BMI categories was no more than $10 \%$, but grew to $29 \%$ at 18 years. Just $40 \%$ of men who were underweight at initial examination in the NHANES survived 18 years, compared with $69 \%$ of overweight 
men. The optimal BMI for survival increased from a range of $20.6-23.6$ in the Union Army cohorts to $22.7-27.3$ in the NHANES cohorts. However, in both groups the optimal BMI for survival was in the middle of the distribution, the BMI-mortality relationship was again Ushaped. Using a larger sample with different age restriction, Linares and Su also examined survival rates over 20 years (Linares and $\mathrm{Su}, 2005$ ). They also found a U-shaped relationship between body mass and mortality. Similarly to Henderson, they categorized body mass into the modern BMI categories of underweight $(<20)$, normal weight $(20-25)$, overweight $(25$ 30) and obese (30+). Mortality was minimized with a normal BMI between 20 and 25, paralleling the results that Henderson obtained with the same dataset. BMI was less strongly associated with deaths more than 9 years after measurement, emphasizing that current weight is most predictive of mortality.

The results obtained in the Union Army datasets are broadly paralleled by findings on Amherst College students (Murray, 1997). Men who were extremely thin or fat had a significantly elevated mortality risk, compared to men with a normal weight. Because the men were weighed at college in their early 20s, Murray's research examined the effect of early-adult body composition on survival to age 70. Even after controlling for height, men with a BMI below 18 were one-third more likely to die before age 70 than men of normal weight or moderate underweight (a BMI between 18 and 20). Men who were overweight (BMI > 25) were $45 \%$ more likely to die before age 70 than normal or moderately underweight men. Like the authors using the Union Army dataset, Murray concluded that the BMI-mortality relationship was not significantly different in historical populations than contemporary ones. 
A final piece of historical evidence on the weight-mortality relationship comes from a study of Scottish university students born in the 1920s, and followed until 2002 (Jeffreys, McCarron et al., 2003). The men, who were students at Glasgow University in 1948, were weighed in-person in 1948 and reported their weight in a postal questionnaire in the mid1960s. Although the two weight measures were not collected in the same way, the independent timing of the two weight measures distinguishes this research from the Union Army research, where men who visited the doctor more frequently were weighed more frequently. Unlike the Union Army based research Jeffreys et al found that weight in early adulthood was more strongly predictive of later-life mortality than mid-adult weight. Weight was most strongly predictive of cardiovascular disease mortality, and only moderately predictive of cancer mortality. Weight gain between early and mid-adulthood was not predictive of mortality. The failure to find an association between weight gain and mortality is inconsistent with the majority of the epidemiological evidence, and is likely to be due to mid-adult weight being self-reported.

\subsection{Weight and Height Together}

Following the literature we have, to this point, discussed separately the relationships among health, height and weight. Yet by definition any research that uses the body mass index has information on stature. It follows that the relationship between height and mortality, and between body mass and mortality, are interdependent. Treating the relationships independently implies that the BMI-mortality relationship is stable across the height distribution, This assumption should be tested (Fogel, 2009). Put slightly differently, we need to investigate if each increment of height may require different increments of weight to maintain constant health. 
Empirically, a key issue is whether people who are short but adequately nourished-as measured by BMI—are at a higher risk of death. People living through periods of rapid economic change—-such as in contemporary developing countries, or now developed countries in the late nineteenth and early twentieth centuries-may be poorly nourished in childhood and thus short, but well nourished in adulthood and thus have a BMI in the healthy range. In a longitudinal perspective the question is whether early life deprivation reflected in short stature could be compensated for by adequate nutrition later on (Fogel, 1994; Fogel and Costa, 1997).

Specifying mortality risk as a function of height, weight (and other control variables) is straightforward. Depicting the relationship for constant values of other controls requires an iso-mortality surface to be displayed graphically in two dimensions. Despite the straightforward nature of the iso-mortality curve, most research still depicts BMI-mortality curves (Henderson, 2005; Linares and Su, 2005; Su, 2005). A good example of the isomortality surface comes from Robert Fogel's 2004 book The escape from hunger and premature death (Fogel, 2004). The iso-mortality curves are formed in height-weight space (Figure 1), and are estimated from Waaler's 1984 data. The solid elliptical curves depict those combinations of height and weight (and thus BMI) that give a constant mortality risk. The dashed lines are lines of constant BMI (height/weight ${ }^{2}$ ). Connecting the minima of each [solid] ellipse shows what weight minimizes risk at each height. Note that at the bottom, the line connecting the minima of each iso-mortality curves is to the right of the line depicting $\mathrm{BMI}=25$, and then shifts across the line of $\mathrm{BMI}=25$. Two important conclusions follow from this. First, even at the same healthy BMI short men are at a higher risk of death than tall men. Second, the BMI that minimizes mortality risk is not constant over height. For shorter 
men $(175 \mathrm{~cm})$, it is better to a little heavier, with a BMI of around 26 . But for tall men it is better to be thin, with an ideal BMI of 22 for a man of $190 \mathrm{~cm}$ or taller.

\section{[INSERT FIGURE 1 ABOUT HERE]}

This framework provides a way of recognizing that the relationship between body composition and health need not be an historical constant. Determining how the relationship has changed across time, and what the costs and benefits of that change have been is an appropriate task for economic historians. It is particularly important for future research to address more explicitly the question of how the relationship has changed across cohorts, similar to the research of Flegal and Gregg (Gregg, Cheng et al., 2005; Flegal, Graubard et al., 2007). Higher BMI values are strongly associated with increases in adiposity or fatness, placing greater strain on the circulatory system. Consequently higher BMI values are most strongly associated with mortality from cardiovascular diseases. While there is some modern evidence of an association between increased BMI and some forms of cancer, the historical evidence for this is very weak.

Historical research by economists has also demonstrated the mortality risks of being significantly underweight, a concern somewhat foreign to western populations in the past three decades. However, the etiology of mortality risk for underweight and overweight individuals is somewhat different. A very low body mass index is associated with higher mortality risk, but underweight itself is not really the cause of death. Morbidities such as gastrointestinal diseases or cancer cause the individual to have problems with eating or retaining nutrients, and the individual loses weight. Underweight is a symptom of the illness. Conversely being overweight is a cause of cardiovascular problems, and leads indirectly to 
mortality. Overweight is a cause of both the illness and mortality. Historical research has confirmed the findings of modern research that the extremes of the BMI distribution can have higher mortality risk. But in both the nineteenth century (gastrointestinal) and the twentieth century (smoking) the association of leanness with mortality is not likely to be causal.

Cliometric research has complemented the modern epidemiological literature by showing that the mortality and morbidity risk of overweight and obesity has changed over time. At least within the United States for which there is evidence across more than a century, the mortality risk of being moderately overweight appears to have dropped in the past 40 years. Precisely because the literature has shown these results to vary over time within one country with technological and behavioral change, we should not expect that the mortality risk and costs of being overweight would be the same elsewhere. Documenting changes over a century or more in the BMI-mortality and height-mortality relationship in other countries is an important area of research for economic historians.

\section{Discussion and conclusion}

Historical anthropometric research continues to expand and, increasingly, to develop an explicit longitudinal dimension. Our survey of recent work in this area, most of which are longitudinal studies of human growth and health, spans the social and health sciences (principally history, economics and epidemiology). Research in this area, as Steckel (1998) observes, benefits greatly from communication across the disciplines. Health scientists increasingly exploit historical sources while social science historians are influenced by the advance of knowledge in the health sciences. 
Economic historians are making a particularly important contribution of documenting how the shape of BMI - mortality relationship has changed across cohorts, periods and countries. This is a useful corrective to the presumption in some medical (not epidemiological) literature of a stable or universal biological relationship. The nineteenth century attracts particular interest in part because professional medical care was limited, infectious disease was common and patterns of economic change were very different than those before or after. The confounding of the BMI-mortality relationship by smoking was less prevalent although admittedly alcohol consumption was greater in the nineteenth than in the twentieth century. Of course nineteenth century results will not be any more universal than those arising from more recent experience.

The economic historical approach also makes a significant contribution to the preservation and re-analysis of early medical and health studies and to the construction of longitudinal data by linking administrative sources of health information to population censuses and registers. The importance of the Union Army datasets is apparent at several points in the above survey. While this research will continue to be influential, the economic and social environment of the United States differed from that of other countries. If the relative price of food differed significantly in the United States from that elsewhere, for example, we would expect different patterns of food consumption to influence trends in BMI and health.

Historical sources are often complex in different ways than modern survey data because the former were not collected in a fully controlled way and for the most part were not collected in order to support scientific research. Of course both classes of data are sensitive to the challenges of attaining sample size for robust estimation and the need to consider selection into the sample and out of the sample through mortality, migration etc. Many, but not all, 
modern surveys rely on a self-reporting of body measurements that may involve some misrepresentation of height, weight, and by derivation body mass index (Gorber, Tremblay et al., 2007). Until the age of 50 contemporary American men tend to overstate their height by about a centimeter, whereas women are relatively accurate. Individuals over 50 years old may misrepresent stature because they are beginning to shrink. Men slightly overstate their own weight, whereas women generally understate their weight until their late 70s (Thomas and Frankenberg, 2002).

The prison and military records used by economic historians generally rely on measurement by independent observers. Although the problem of self-reporting is less pressing in these historical sources, other challenges may present themselves. For example it is important to know if historical heights and weights were recorded with shoes and heavy clothing removed (men's shoes or boots can easily add $2-3 \mathrm{~cm}$ to measured heights, and a kilogram to weight). The precision of measurement unit may also be important. Heights recorded to the $1 / 4 \mathrm{inch}$ $(0.6 \mathrm{~cm})$ signal attentiveness to proper measurement. Heights recorded only to the whole inch are less desirable, as the historian has no way of knowing whether measurements were rounded up or down. Rounding increases imprecision; fortunately it need not bias the mean. A bigger concern might be inconsistency in methods of measurement across data sources, and across time within the same source (Shlomowitz, 2007). Age heaping is a common problem in historical sources although its significance for inference is likely to be limited to analysis of specific events in particular years; analysis of trends over five- or ten-year birth cohorts is largely unaffected.

The precise dating of exposure to environmental or economic shocks is important for an emerging area of anthropometric research that examines the effects of conditions in-utero 
(Lumey and Van Poppel, 1994; Lumey, 1998; Almond, 2006; Mazumder, Almond et al., 2009; Song, 2009; Nelson, forthcoming). Epidemiological research shows that there are critical periods in human growth, from birth to three years of age and in adolescence (Bogin, 1999b; Gillman, 2004). An adverse shock during a critical period may have persisting consequences. Recent research in labour economics has shown that there are persistent effects for young adults who enter the labor market during a recession. A parallel question for anthropometric research is if the Great Depression, for example, had differential impacts on people who entered it during early or late childhood. Longitudinal studies in anthropometric history exploit these insights to measure when and how environmental and economic shocks matter.

Social surveys, censuses, the registration of demographic events and routine government data collection for social and health services since the 1850 s have created a rich potential for further longitudinal anthropometric research on populations in many countries. The creation of longitudinal samples from diverse sources is a significant task, as Ferrie et al's early life indicator project makes clear, but the payoff from well-designed studies is high (Ferrie, Rolf et al., 2009). It will be especially valuable to assess with evidence elsewhere the generalizability of the relationship between body composition and health already demonstrated for the U.S. from Union Army records.

The potential for construction of longitudinal samples even extends to inter-generational data. Data that span generations in turn raises the question of the interaction between genes and the environment (North and Martin, 2008; Conley, 2009). Many historical sources offer limited information with which to infer genetic background. Own and parental birthplace, and indicators of ethnicity are variables that were collected historically, and could proxy for 
genetic influences. The systematic compilation of family genealogies and samples that include siblings might be used to separate genetic and environmental influences. For example, research by John Parman uses a dataset of brothers who served in World War II to examine the influence of height on educational attainment (Parman, 2009). Assembling this kind of data from historical records is possible in other countries and contexts. Data collection is likely to be even more involved than for other historical longitudinal research, as links must be made not only between one individual over time, but a sibling relationship must be identified. The use of sibling datasets may also permit some insights into questions of intra-household resource allocation.

Incorporating genetic influences into anthropometric studies, and using longitudinal-based anthropometric evidence in genetic studies, is likely to be more straightforward for studies of stature than weight. At an individual level genetic inheritance influences stature more than than weight. Incorporating genetic influences will not solve all of the inferential challenges in anthropometric research. Without information on individual childhood conditions, stature will remain a reduced form for nutritional standards over the growth period. Inferential challenges remain for the study of weight or body mass and health, both morbidity and mortality. For example, evidence of a connection between body mass at time $t$ and mortality by time $t+x$ may be powerless to explain what happens in the intervening $x$ years. Two underlying relationships are possible. First, adult body mass at time $t$ may be predictive of mortality by $t+x$ because strain is being placed on the circulatory system at time $t$. In this case body mass at time $t$ has a causal relationship with mortality. Second, body mass at time $t$ might have no independent effect on mortality, but be statistically predictive of body mass later in the interval $(t, t+x)$ that does have a physiological impact on mortality. Interpretation of historical results can be guided by cautious extrapolation from the current medical and 
epidemiological literature. Establishing a causal relationship between body composition and mortality in historical studies is a continuing challenge.

This paper has surveyed the broad contribution of anthropometric history to understanding historical trends in living standards and the growing importance of historical longitudinal data to the interdisciplinary literature about human health. The extent and richness of both anthropometric and longitudinal research have expanded quickly during the past two decades, especially in economic history. Research opportunities continue to increase. We are in the early stages of a trajectory that will continue to contribute in unique and important ways to knowledge in history, economics and the social and health sciences. 


\section{Acknowledgements}

We gratefully acknowledge helpful comments received from Richard Steckel, Bertie Lumey and the editor and referees of this journal and financial support from the Royal Soceity of New Zealand, the Health Research Council of New Zealand, the Social Sciences and Humanities Research Council of Canada and our two universities. 


\section{References}

Allison, D.B., Zhu, S.K., et al. (2002) Differential associations of body mass index and adiposity with all-cause mortality among men in the first and second National Health and Nutrition Examination Surveys (NHANES I and NHANES II) follow-up studies. International Journal of Obesity \& Related Metabolic Disorders: Journal of the International Association for the Study of Obesity 26: 410-6.

Almond, D. (2006) Is the 1918 influenza pandemic over? Long-term effects of in utero influenza exposure in the post-1940 U.S. population. Journal of Political Economy 114: 672-712.

Alter, G., Neven, M., et al. (2004) Stature in Transition: A Micro-Level Study from Nineteenth-Century Belgium. Social Science History 28: 231-248.

Aronson, N. (1982) Nutrition as a Social Problem: A Case Study of Entrepreneurial Strategy in Science. Social Problems 29: 474-487.

Barker, D.J.P. (1992) Fetal and infant origins of adult disease : papers. London, British Medical Journal.

Barker, D.J.P. (1998) Mothers, Babies, and Health in Later Life. London, Churchill Livingstone.

Barker, D.J.P. (2004) The Developmental Origins of Adult Disease. Journal of the American College of Nutrition 23: 588S-595S.

Baten, J. and Murray, J. (2000) Heights of Men and Women in Nineteenth-Century Bavaria: Economic, Nutritional, and Disease Influences. Explorations in Economic History 37: 351-361.

Batty, G.D., Lawlor, D.A., et al. (2005) Accuracy of adults' recall of childhood social class: findings from the Aberdeen children of the 1950s study Journal of Epidemiology \& Community Health 59: 898-903.

Batty, G.D., Shipley, M.J., et al. (2009) Height, wealth, and health: An overview with new data from three longitudinal studies. Economics \& Human Biology 7: 137-152.

Batty, G.D., Shipley, M.J., et al. (2006) Adult height in relation to mortality from 14 cancer sites in men in London (UK): evidence from the original Whitehall study. Annals of Oncology 17: 157-66.

Ben-Shlomo, Y. and Kuh, D. (2004) Conclusions. A life course approach to chronic disease epidemiology. Kuh, D. and Ben-Shlomo, Y. Oxford, Oxford University Press: 446464.

Berney, L.R. and Blane, D.B. (1997) Collecting retrospective data: Accuracy of recall after 50 years judged against historical records. Social Science \& Medicine 45: 1519-1525.

Blane, D., Berney, L., et al. (1999) Reconstructing the life course: health during early old age in a follow-up study based on the Boyd Orr cohort. Public Health 113: 117-124.

Bogin, B. (1999a) Evolutionary Perspective On Human Growth. Annual Review of Anthropology 28: 109-153.

Bogin, B. (1999b) Patterns of human growth. Cambridge, Cambridge University Press.

Bowditch, H.P. (1877) The growth of children. Boston, Massachusetts State Board of Health.

Brennan, L., Macdonald, J., et al. (1994) A long run decline in final adult female height in India. Man in India 84: 9-13.

Calle, E.E., Thun, M.J., et al. (1999) Body-Mass Index and Mortality in a Prospective Cohort of U.S. Aduts. New England Journal of Medicine 341: 1097-1105.

Coelho, P. and McGuire, R. (2000) Diets versus diseases: the anthropometrics of slave children. The Journal of Economic History 60: 232-246. 
Conley, D. (2009) The Promise and Challenges of Incorporating Genetic Data into Longitudinal Social Science Surveys and Research. Biodemography and Social Biology 55: 238-251.

Corrada, M., Kawas, C., et al. (2006) Association of body mass index and weight change with all-cause mortality in the elderly. American Journal of Epidemiology 163: 938.

Costa, D. (1993) Height, weight, wartime stress, and older age mortality: evidence from the Union Army records. Explorations in Economic History 30: 424-449.

Costa, D. (2004) The measure of man and older age mortality: Evidence from the Gould Sample. The Journal of Economic History 64: 1-23.

Costa, D.L. (1996) Health and Labor Force Participation of Older Men, 1900-1991. Journal of Economic History 56: 62-89.

Coughlin, S.S. (1990) Recall bias in epidemiologic studies. Journal of Clinical Epidemiology 43: 87-91.

Craig, L., Goodwin, B., et al. (2004) The effect of mechanical refrigeration on nutrition in the United States. Social Science History 28: 325-336.

Cranfield, J. and Inwood, K. (2007) The great transformation: A long-run perspective on physical well-being in Canada. Economics and Human Biology 5: 204-228.

Cutler, D.M., Glaeser, E.L., et al. (2003) Why have Americans become more obese? Journal of Economic Perspectives 17: 93-118.

Czerniawski, A.M. (2007) From Average to Ideal: The Evolution of the Height and Weight Table in the United States, 1836-1943. Social Science History 31: 273-296.

Davey Smith, G., Hart, C., et al. (2000) Height and risk of death among men and women: aetiological implications of associations with cardiorespiratory disease and cancer mortality. Journal of Epidemiology \& Community Health 54: 97-103.

Davey Smith, G. and Lynch, J.W. (2004) Life course approaches to socioeconomic differentials in health. A life course approach to chronic disease epidemiology. Kuh, D. and Ben-Shlomo, Y. Oxford, Oxford University Press: 77-96.

Davey Smith, G., Sterne, J.A.C., et al. (2009) The association between BMI and mortality using offspring BMI as an indicator of own BMI: large intergenerational mortality study. BMJ 339: b5043-.

Deaton, A. (2008) Height, Health, and Inequality: The Distribution of Adult Heights in India. American Economic Review 98: 468-744.

Elford, J. and Ben-Shlomo, Y. (2004) Geography and migration with special reference to cardiovascular disease. A life course approach to chronic disease epidemiology. Kuh, D. and Ben-Shlomo, Y. Oxford, Oxford University Press: 144-164.

Engeland, A., Bjorge, T., et al. (2003) Height and body mass index in relation to total mortality. Epidemiology 14: 293-9.

Engerman, S. (1976) The height of slaves in the United States. Local Population Studies 16: 45-49.

Engerman, S. (2004) Personal reflections on the 1982 Special Anthropometric Issue of Social Science History. Social Science History 28: 345-349.

Eveleth, P.B. (1975) Differences between ethnic groups in the degree of dimorphism. Annals of Human Biology 2: 35-39.

Eveleth, P.B. and Tanner, J.M. (1990) Worldwide variation in human growth. Cambridge, Cambridge University Press.

Faulkner, F.T. and Tanner, J.M. (1986) Human Growth: A comprehensive treatise. New York, Plexum Press.

Felson, D.T. (1996) Weight and osteoarthritis. American Journal of Clinical Nutrition 63: $430 \mathrm{~S}$. 
Ferraro, K.F., Su, Y., et al. (2002) Body mass index and disability in adulthood: a 20-year panel study. American Journal of Public Health 92: 834.

Ferrie, J., Rolf, K., et al. (2009) '... Healthy, Wealthy, and Wise? Physical, Economic and Cognitive Effects of Early Life Conditions on Later Life Outcomes in the U.S., 19152005.' Long-run Impact of Early Life Events II Workshop, National Poverty Center, University of Michigan, March 2009.

Ferrie, J.P. (1999) Yankeys Now: Immigrants in the Antebellum United States. New York, Oxford University Press.

Flegal, K.M., Graubard, B.I., et al. (2007) Cause-Specific Excess Deaths Associated With Underweight, Overweight, and Obesity. JAMA 298: 2028-2037.

Fleurbaey, M. (2009) Beyond GDP: The Quest for a Measure of Social Welfare. Journal of Economic Literature 47: 1029-1075.

Floud, R. (1998) 'Height, Weight, and Body Mass of the British Population Since 1820.' NBER Historical Working Paper 108. Cambridge: National Bureau of Economic Research.

Floud, R., Wachter, K., et al. (1990) Height, Health and History: Nutritional Status in the United Kingdom, 1750-1980. Cambridge, Cambridge University Press.

Fogel, R. (1994) Economic growth, population theory, and physiology: The bearing of longterm processes on the making of economic policy. The American Economic Review: 369-395.

Fogel, R.W. (1993) New sources and new techniques for the study of secular trends in nutritional status, health, mortality and the process of aging. Historical Methods 26: $5-43$.

Fogel, R.W. (2004) The escape from hunger and premature death, 1700-2100. Cambridge, Cambridge University Press.

Fogel, R.W. (2009) 'Some Common Analytical Errors in Explanations for the Secular Improvement in Health and Longevity.' Chicago: Center for Population Economics, University of Chicago.

Fogel, R.W. and Costa, D.L. (1997) A theory of technophysio evolution, with some implications for forecasting population, health care costs, and pension costs. Demography 34: 49-66.

Fogel, R.W., Engerman, S.L., et al. (1982) Exploring The Uses Of Data On Height: The Analysis Of Long-term Trends In Nutrition, Labor Welfare, And Labor Productivity. Social Science History 6: 401-421.

Forouhi, N., Hall, E., et al. (2004) Life course approaches to diabetes. A life course approach to chronic disease epidemiology. Kuh, D. and Ben-Shlomo, Y. Oxford, Oxford University Press: 165-187.

Frayer, D.W. and Wolpoff, M.H. (1985) Sexual Dimorphism. Annual Review of Anthropology 14: 429-473.

Friedenreich, C.M. (1994) Improving long-term recall in epidemiologic studies. Epidemiology 5: 1-4.

Frijters, P., Hatton, T.J., et al. (2010) Childhood Economic Conditions and Length of Life:, Evidence from the UK Boyd Orr Cohort, 1937-2005. Journal of Health Economics 29: 39-47.

Gallman, R. (1996) Dietary change in antebellum America. The Journal of Economic History 56: 193-201.

Gaulin, S. and Boster, J. (1985) Cross-cultural differences in sexual dimorphism: Is there any variance to be explained? Ethology and Sociobiology 6: 219-225. 
Gillman, M.W. (2004) A life course approach to obesity. A life course approach to chronic disease epidemiology. Kuh, D. and Ben-Shlomo, Y. Oxford, Oxford University Press: 189-217.

Giskes, K., Kunst, A., et al. (2005) Trends in smoking behaviour between 1985 and 2000 in nine European countries by education. Journal of Epidemiology and Community Health 59: 395.

Goeken, R. (2010 forthcoming) New Methods of Census Record Linking. Historical Methods 43.

Gorber, S.C., Tremblay, M., et al. (2007) A comparison of direct vs. self-report measures for assessing height, weight and body mass index: a systematic review. Obesity Reviews 8: 307-326.

Gorsky, M., Harris, B., et al. (2006) Age, Sickness, and Longevity in the Late Nineteenth and the Early Twentieth Centuries: Evidence from the Hampshire Friendly Society. Social Science History 30: 571-600.

Gray, J.P. and Wolfe, L.D. (1980) Height and sexual dimorphism of stature among human societies. American Journal of Physical Anthropology 53: 441-456.

Gregg, E.W., Cheng, Y.J., et al. (2005) Secular Trends in Cardiovascular Disease Risk Factors According to Body Mass Index in US Adults. JAMA 293: 1868-1874.

Gustafsson, A. and Lindenfors, P. (2004) Human size evolution: no evolutionary allometric relationship between male and female stature. Journal of Human Evolution 47: 253266.

Gustafsson, A., Werdelin, L., et al. (2007) Stature and Sexual Stature Dimorphism in Sweden, from the 10th to the End of the 20th Century. American Journal of Human Biology 19: 861-870.

Haas, S.A. (2007) The Long-Term Effects of Poor Childhood Health: An Assessment and Application of Retrospective Reports. Demography 44: 113-135.

Haines, M.R. (2001) The Urban Mortality Transition In The United States, 1800-1940. Annales de démographie historique: 33-64.

Haines, M.R. (2004) Growing Incomes, Shrinking People - Can Economic Development Be Hazardous To Your Health? Historical Evidence For The United States, England, And The Netherlands In The Nineteenth Century. Social Science History 28: 249-270.

Haines, M.R., Craig, L.A., et al. (2003) The Short And The Dead: Nutrition, Mortality, And The "Antebellum Puzzle" In The United States. Journal of Economic History 63: 382413.

Hardy, J.B. (2003) The Collaborative Perinatal Project: lessons and legacy. Annals of Epidemiology 13: 503-511.

Harris, B. (1995). "The health of the schoolchild : a history of the school medical service in England and Wales."

Harris, B. (2009) Gender, Health and Welfare in England Since Industrialization. Research in Economic History 26: 157-204.

Hart, C.L., Taylor, M.D., et al. (2004) Childhood IQ and cardiovascular disease in adulthood: prospective observational study linking the Scottish Mental Survey 1932 and the Midspan studies. Social Science \& Medicine 59: 2131-2138.

Hatton, T.J. and Martin, R.M. (2010) The effects on stature of poverty, family size, and birth order: British children in the 1930s. Oxford Economic Papers 62: 157-184.

Heltberg, R. (2009) Malnutrition, poverty, and economic growth. Health Economics 18: S77S88.

Henderson, R.M. (2005) The bigger the healthier: Are the limits of BMI risk changing over time? Economics and Human Biology 3: 339-366. 
Himes, J.H. (2006) Long-term longitudinal studies and implications for the development of an international growth reference for children and adolescents. Food and Nutrition Bulletin 27: S199-S211.

Hoffmans, M., Kromhout, D., et al. (1989) Body Mass Index at the age of 18 and its effects on 32-year-mortality from coronary heart disease and cancer. A nested case-control study among the entire 1932 Dutch male birth cohort. Journal of Clinical Epidemiology 42: 513.

Hoffmans, M.D.A.F., Kromhout, D., et al. (1988) The impact of body mass index of 78,612 18-year-old men on 32-year mortality from all causes. Journal of Clinical Epidemiology 41: 749-756.

Holden, C. and Mace, R. (1999) Sexual dimorphism in stature and women's work: A phylogenetic cross-cultural analysis. American Journal of Physical Anthropology 110: 27-45.

Holland, P., Berney, L., et al. (2000) Life course accumulation of disadvantage: childhood health and hazard exposure during adulthood. Social Science \& Medicine 50: 12851295.

Horrell, S., Meredith, D., et al. (2007) Anthropometric measures of living standards and gender inequality in nineteenth century Britain. Local Population Studies 79: 66-74.

Horrell, S., Meredith, D., et al. (2009) Measuring misery: Body mass, ageing and gender inequality in Victorian London. Explorations in Economic History 46: 93-119.

Inwood, K., Oxley, L., et al. (2009). Rather above than under the common size? Stature and Living Standards in New Zealand. World Economic History Congress. Utrecht.

Inwood, K., Oxley, L., et al. (2010 forthcoming) Physical stature in nineteenth century New Zealand-a preliminary interpretation. Australian Economic History Review 50.

Jeffreys, M., McCarron, P., et al. (2003) Body mass index in early and mid-adulthood, and subsequent mortality: a historical cohort study. International Journal of Obesity 27: 1391-1397.

Jia, H. and Lubetkin, E. (2005) The impact of obesity on health-related quality-of-life in the general adult US population. Journal of public health 27: 156-64.

Johansen, S. (2000) Family Men: Middle-Class Fatherhood in Industrializing America. New York, Routledge.

Johansson, S. (2004) The health transition: the cultural inflation of morbidity during the decline of mortality. Health Transition Review 1: 39-65.

Jousilahti, P., Tuomilehto, J., et al. (2000) Relation of Adult Height to Cause-specific and Total Mortality: A Prospective Follow-up Study of 31, 199 Middle-aged Men and Women in Finland. Am. J. Epidemiol. 151: 1112-1120.

Kanazawa, S. and Novak, D. (2004) Human sexual dimorphism in size may be triggered by environmental cues. Journal of Biosocial Science 37: 657-665.

Kauhanen, L., Lakka, H.-M., et al. (2006) Social disadvantages in childhood and risk of allcause death and cardiovascular disease in later life: a comparison of historical and retrospective childhood information. Int. J. Epidemiol. 35: 962-968.

Keys, A., Aravanis, C., et al. (1972) Coronary heart disease: overweight and obesity as risk factors. Annals of Internal Medicine 77: 15.

Klebanoff, M.A. (2009) The Collaborative Perinatal Project: a 50-year retrospective. Paediatric and perinatal epidemiology 23: 2-8.

Komlos, J. (1987) The height and weight of West Point cadets: dietary change in antebellum America. Journal of Economic History 47: 897-927.

Komlos, J. (1996) Anomalies in Economic History: Toward a Resolution of the" Antebellum Puzzle". The Journal of Economic History 56: 202-214. 
Komlos, J. (1998) Shrinking in a Growing Economy? The Mystery of Physical Stature during the Industrial Revolution. Journal of Economic History 58: 779-802.

Komlos, J. and Ritschl, A. (1995) Holy Days, Work Days, and the Standard of Living in the Habsburg Monarchy. Journal of Interdisciplinary History 26: 57-66.

Kuh, D. and Ben-Shlomo, Y. (2004) The life course and adult chronic disease: an historical perspective with particular reference to coronary heart disease. A life course approach to chronic disease epidemiology. Kuh, D. and Ben-Shlomo, Y. Oxford, Oxford University Press: 15-40.

Kuh, D. and Hardy, R. (2004) A life course approach to women's health: does the past predict the present? A life course approach to women's health. Kuh, D. and Hardy, R. Oxford, Oxford University Press 3-22.

Kuh, D. and Smith, G.D. (1993) When is mortality risk determined? Historical insights into a current debate. Social History of Medicine 6: 101-123.

Lakdawalla, D. and Philipson, T. (2009) The growth of obesity and technological change. Economics \& Human Biology 7: 283-293.

Lawlor, D.A., Ben-Shlomo, Y., et al. (2004) Pre-adult influences on cardiovascular disease. A life course approach to chronic disease epidemiology. Kuh, D. and Ben-Shlomo, Y. Oxford, Oxford University Press: 41-76.

Lawlor, D.A., Martin, R.M., et al. (2006) Association of body mass index measured in childhood, adolescence, and young adulthood with risk of ischemic heart disease and stroke: findings from 3 historical cohort studies. Am J Clin Nutr 83: 767-773.

Lee, C., Barzi, F., et al. (2009) Adult height and the risks of cardiovascular disease and major causes of death in the Asia-Pacific region: 21000 deaths in 510000 men and women. International Journal of Epidemiology 38: 1060.

Lee, I.-M., Manson, J.E., et al. (1993) Body Weight and Mortality: A 27-Year Follow-up of Middle-aged Men. JAMA 270: 2823-2828.

Leigh, S.R. (2001) Evolution of Human Growth. Evolutionary Anthropology 10: 221-236.

Leigh, S.R. and Park, P.B. (1998) Evolution of Human Growth Prolongation. American Journal of Physical Anthropology 107: 331-350.

Leon, D., Lawlor, D., et al. (2006) Cohort profile: the Aberdeen children of the 1950s study. International Journal of Epidemiology 35: 549.

Linares, C. and Su, D. (2005) Body mass index and health among Union Army veterans: 1891-1905. Economics and Human Biology 3: 367-387.

Lindsted, K., Tonstad, S., et al. (1991) Body mass index and patterns of mortality among Seventh-day Adventist men. Int J Obes 15: 397-406.

Logan, T.D. (2006) Food, nutrition, and substitution in the late nineteenth century. Explorations in Economic History 43: 527-545.

Logan, T.D. (2009) The transformation of hunger: The demand for calories past and present. The Journal of Economic History 69: 388-408.

Lumey, L. (1998) Reproductive outcomes in women prenatally exposed to undernutrition: a review of findings from the Dutch famine birth cohort. Proceedings of the Nutrition Society 57: 129-135.

Lumey, L. and Van Poppel, F. (1994) The Dutch famine of 1944-45: mortality and morbidity in past and present generations. Social History of Medicine 7: 229.

Lumey, L.H., Stein, A.D., et al. (2010 forthcoming) Prenatal Famine and Adult Physical and Mental Health. Annual Review of Public Health.

Martin, R.M., Gunnell, D., et al. (2005) Cohort Profile: The Boyd Orr cohort--an historical cohort study based on the 65 year follow-up of the Carnegie Survey of Diet and Health (1937-39). Int. J. Epidemiol. 34: 742-749. 
Mazumder, B., Almond, D., et al. (2009) Lingering prenatal effects of the 1918 influenza pandemic on cardiovascular disease. Journal of Developmental Origins of Health and Disease 1: 1-9.

McCalman, J., Morley, R., et al. (2008) A health transition: Birth weights, households and survival in an Australian working-class population sample born 1857-1900. Social Science \& Medicine 66: 1070-1083.

McEvoy, B.P. and Visscher, P.M. (2009) Genetics of human height. Economics and Human Biology 7: 294-306.

McGee, D.L. and Diverse Population Collaboration (2005) Body mass index and mortality: a meta-analysis based on person-level data from twenty-six observational studies. Annals of Epidemiology 15: 87-97.

Mednick, S.A. and Mednick, B. (1984) A Brief History of North American Longitudinal Research. Handbook of Longitudinal Research. Sarnoff, A.M., Harway, M. and Finello, K.M. New York Praeger: 19-21.

Mehta, N.K. and Chang, V.W. (2009) Mortality Attributable to Obesity Among Middle-Aged Adults in the United States Demography 46: 851-872.

Mei, Z., Grummer-Strawn, L.M., et al. (2004) Shifts in Percentiles of Growth During Early Childhood: Analysis of Longitudinal Data From the California Child Health and Development Study. Pediatrics 113: e617-627.

Moradi, A. and Baten, J. (2005) Inequality in Sub-Saharan Africa: New data and new insights from anthropometric estimates. World Development 33: 1233-1265.

Murphy, M. (2009) Where have all the children gone? Women's reports of more childlessness at older ages than when they were younger in a large-scale continuous household survey in Britain. Population Studies 63: 115-133.

Murray, J.E. (1997) Standards of the present for people of the past: Height, weight, and mortality among men of Amherst College, 1834-1949. Journal of Economic History 57: 585-606.

Murray, J.E. (2007) Origins of American health insurance : a history of industrial sickness funds. New Haven, Yale University Press.

Must, A., Spadano, J., et al. (1999) The Disease Burden Associated With Overweight and Obesity. Journal of the American Medical Association 282: 1523-1529.

Nelson, R.E. (forthcoming) Testing the Fetal Origins Hypothesis in a developing country: evidence from the 1918 Influenza Pandemic. Health Economics.

Nettle, D. (2002) Women's height, reproductive success and the evolution of sexual dimorphism in modern humans. Proceedings of the Royal Society of London. Series B: Biological Sciences 269: 1919.

Nicholas, S. and Oxley, D. (1993) The living standards of women during the industrial revolution, 1795-1820. Economic History Review New Series 46: 723-749.

North, K.E. and Martin, L.J. (2008) The Importance of Gene-Environment Interaction: Implications for Social Scientists Sociological Methods \& Research 37: 164-200.

Oddy, D.J. (1970) Working-Class Diets in Late Nineteenth-Century Britain. The Economic History Review 23: 314-323.

Osler, M., Godtfredsen, N., et al. (2008) Childhood social circumstances and health behaviour in midlife: the Metropolit 1953 Danish male birth cohort. International Journal of Epidemiology 37: 1367.

Owen, C., Whincup, P., et al. (2009) Is body mass index before middle age related to coronary heart disease risk in later life? Evidence from observational studies. International Journal of Obesity 33: 866-877.

Parman, J. (2009) 'Childhood Health and Educational Attainment: Evidence from (Genetic) Brothers in Arms.' Davis: Department of Economics, University of California, Davis. 
Philipson, T. and Posner, R. (2003) The long-run growth in obesity as a function of technological change. Perspectives in Biology and Medicine 46: 87-107.

Pierce, J. (1989) International comparisons of trends in cigarette smoking prevalence. American Journal of Public Health 79: 152.

Pool, I. (1991) Te Iwi Maori : a New Zealand population past present \& projected. Auckland, Auckland University Press.

Power, C. and Elliott, J. (2006) Cohort profile: 1958 British birth cohort (National Child Development Study). Int. J. Epidemiol. 35: 34-41.

Preston, S. and Wang, H. (2006) Sex mortality differences in the United States: the role of cohort smoking patterns. Demography 43: 631-646.

Riley, J.C. (1990) The risk of being sick: Morbidity trends in four countries. Population and Development Review 16: 403-432.

Roberts, C. (1879) A Manual of Anthropometry. London, J. \& A. Churchill.

Rogers, A.R. and Mukherjee, A. (1992) Quantitative Genetics of Sexual Dimorphism in Human Body Size. Evolution 46: 226-234.

Rosengren, A., Wedel, H., et al. (1999) Body weight and weight gain during adult life in men in relation to coronary heart disease and mortality: a prospective population study. European heart journal 20: 269.

Sach, T., Barton, G., et al. (2006) The relationship between body mass index and healthrelated quality of life: comparing the EQ-5D, EuroQol VAS and SF-6D. International Journal of Obesity 31: 189-196.

Shlomowitz, R. (2007) Did the mean height of Australian-born men decline in the late nineteenth century? A comment. Economics and Human Biology 5: 484-488.

Silventoinen, K. (2003) Determinants of variation in adult body height. Journal of Biosocial Science 35: 263-285.

Silventoinen, K., Zdravkovic, S., et al. (2006) Association between height and coronary heart disease mortality: a prospective study of 35,000 twin pairs.[see comment]. American Journal of Epidemiology 163: 615-21.

Singh, P., Lindsted, K., et al. (1999) Body weight and mortality among adults who never smoked. American Journal of Epidemiology 150: 1152.

Solomon, C. and Manson, J. (1997) Obesity and mortality: a review of the epidemiologic data. American Journal of Clinical Nutrition 66: 1044S-1050.

Song, S. (2009) Does Famine Have a Long-Term Effect on Cohort Mortality? Evidence From The 1959-1961 Great Leap Forward Famine In China. Journal of Biosocial Science 41: 469-461.

Song, Y., Smith, G., et al. (2003) Adult height and cause-specific mortality: a large prospective study of South Korean men. American Journal of Epidemiology 158: 479.

Sontag, L.W. (1971) The history of longitudinal research: Implications for the future. Child Development 42: 987-1002.

Starr, J.M., Taylor, M.D., et al. (2004) Childhood mental ability and blood pressure at midlife: linking the Scottish Mental Survey 1932 and the Midspan studies. Journal of Hypertension 22: 893-897.

Steckel, R.H. (1979) Slave height profiles from coastwise manifests. Explorations in Economic History 16: 363-380.

Steckel, R.H. (1986) A peculiar population: the nutrition, health, and mortality of American slaves from childhood to maturity. The Journal of Economic History 46: 721-741.

Steckel, R.H. (1995) Stature and the Standard of Living. Journal of Economic Literature 33: 1903-1940.

Steckel, R.H. (1998) Strategic ideas in the rise of the new anthropometric history and their implications for interdisciplinary research. Journal of Economic History 58: 803-821. 
Steckel, R.H. (2000) Diets versus diseases in the anthropometrics of slave children: a reply. The Journal of Economic History 60: 247-259.

Steckel, R.H. (2005) Young adult mortality following severe physiological stress in childhood: Skeletal evidence. Economics and Human Biology 3: 314-328.

Steckel, R.H. (2008) Biological Measures of the Standard of Living. Journal of Economic Perspectives 22: 129-152.

Steckel, R.H. (2009a) 'Children of Adversity: The Care and Feeding of Slave Children.' Columbus: Department of Economics, Ohio State University.

Steckel, R.H. (2009b) Heights and Human Welfare: Recent Developments and New Directions. Explorations in Economic History 46: 1-23.

Steckel, R.H. and Haurin, D.R. (1995) Health and Nutrition in the American Midwest: Evidence from the Height of Ohio National Guardsmen, 1850-1910. Stature, Living Standards, and Economic Development. Komlos, J. Chicago, University of Chicago Press: 117-128.

Steckel, R.H. and Rose, J.C. (2002) The backbone of history : health and nutrition in the Western Hemisphere. Cambridge, U.K. ; New York, Cambridge University Press.

Stenberg, S. and Vagero, D. (2006) Cohort profile: The Stockholm birth cohort of 1953. International Journal of Epidemiology 35: 546.

Stevens, J. (2000) Impact of age on associations between weight and mortality. Nutrition Reviews 58: 129-137.

Stewart, S.T., Cutler, D.M., et al. (2009) Forecasting the Effects of Obesity and Smoking on U.S. Life Expectancy. New England Journal of Medicine 361: 2252-2260.

Sturm, R. and Wells, K. (2001) Does obesity contribute as much to morbidity as poverty or smoking? Public Health 115: 229-235.

$\mathrm{Su}, \mathrm{D}$. (2005) Body mass index and old-age survival: A comparative study between the Union Army Records and the NHANES-I Epidemiological Follow-Up Sample. American Journal of Human Biology 17: 341-354.

Symmons, D.P.M., Bankhead, C.R., et al. (2005) Blood transfusion, smoking, and obesity as risk factors for the development of rheumatoid arthritis. Results from a primary carebased incident case-control study in Norfolk, England. Arthritis \& Rheumatism 40: 1955-1961.

Tanner, J.M. (1981) A history of the study of human growth. Cambridge, Cambridge University Press.

Thernstrom, S. (1964) Poverty and progress; social mobility in a nineteenth century city. Cambridge, Harvard University Press.

Thomas, D. and Frankenberg, E. (2002) The measurement and interpretation of health in social surveys. Summary measures of population health: concepts, ethics, measurement and applications. Murray, C.J.L., Salomon, J.A., Mathers, C.D. and Lopez, A.D. Geneva, World Health Organization.

Trussel, J. and Steckel, R. (1978) The Age of Slaves at Menarche and Their First Birth. Journal of Interdisciplinary History 8: 477-505.

van den Berg, B.J., Christianson, R.E., et al. (1988) The California Child Health and Development Studies of the School of Public Health, University of California at Berkeley. Paediatric and Perinatal Epidemiology 2: 265-282.

Viswanathan, B. and Sharma, V. (2009) Socio-economic Differences in Heights of Adult Indian Women. Journal of Developing Societies 25: 421-455.

Voth, H.-J. (1996) Physical Exertion And Stature In The Habsburg Monarchy, 1730-1800. Journal of Interdisciplinary History 27: 263-275.

Waaler, H. (1984) Height, weight and mortality. The Norwegian experience. Acta Medica Scandinavica Supplementum 679: 1-56. 
Wadsworth, M., Kuh, D., et al. (2006) Cohort profile: the 1946 national birth cohort (MRC national survey of health and development). International Journal of Epidemiology 35: 49.

Wall, W.D. and Williams, H.L. (1970) Longitudinal studies \& the social sciences. London, Heinemann Educational Publishers.

Wannamethee, S.G., Shaper, A.G., et al. (2005) Overweight and obesity and weight change in middle aged men: impact on cardiovascular disease and diabetes. Journal of Epidemiology and Community Health 59: 134-139.

Ward, W.P. (1993) Birth Weight and Economic Growth: Women's Living Standards in the Industrializing West. Chicago, University of Chicago Press.

Wells, J.C.K. (2007) Sexual dimorphism of body composition. Best Practice \& Research Clinical Endocrinology \& Metabolism 21: 415-430.

Whincup, P.H., Cook, D.G., et al. (2004) A life course approach to blood pressure. A life course approach to chronic disease epidemiology. Kuh, D. and Ben-Shlomo, Y. Oxford, Oxford University Press: 218-239.

Whitwell, G. and Nicholas, S. (2001) Weight and Welfare of Australians, 1890-1940. Australian Economic History Review 41: 159-175.

World Health Organization (1999) Obesity: preventing and managing the global epidemic. Geneva, World Health Organization.

Young, C.H., Savola, K.L., et al. (1991) Inventory of longitudinal studies in the social sciences. Newbury Park, Sage Publications. 
Figure 1. Reproduced with permission from Fogel, R.W. (2004) The escape from hunger and premature death, 1700-2100. Cambridge, Cambridge University Press, p. 64 .

\section{Iso-Mortality Curves of Relative Risk of Dying for Height and Weight among Norwegian Males Aged 50-64, with Two Plots}

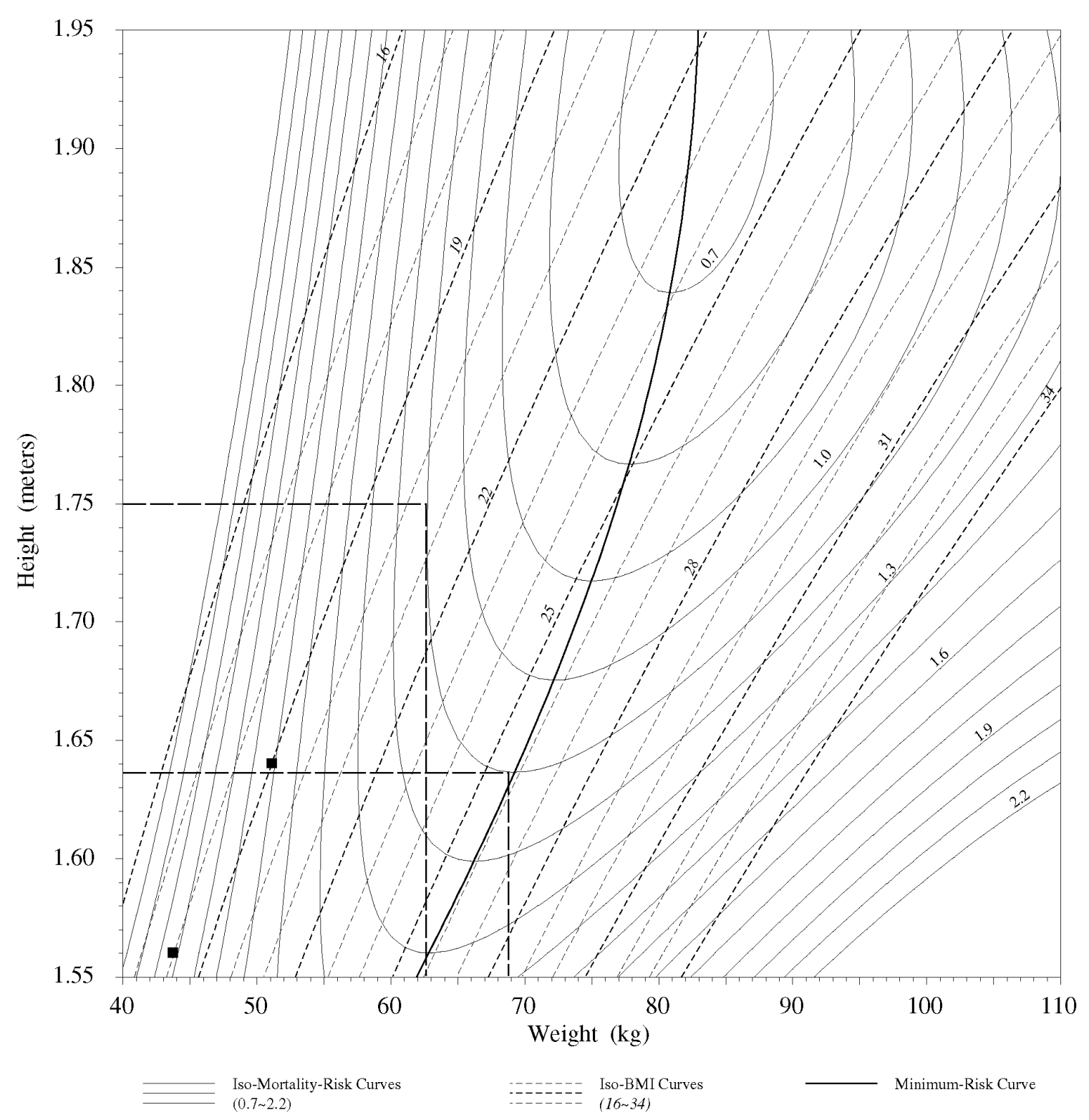

Note: The small dark squares show the effect of a 5 percent reduction in height and weight on the risk of dying. The large rectangles show the increase in weight required to offset the increased risk of dying due to long-term reductions in stature. 
Table One: Maximum Likelihood Truncated (64 inches) Estimation of Stature, NZ-born Soldiers aged 21-49 years in World War Two

Born 1890-1899

Born 1900-1904

Born 1905-1909

Born 1915-1919

Born 1920-1924

Farmer

Labourer, farm

Professional-

Clerical

Labourer, other

Maori Name

Constant

$\mathrm{N}=4939$
Coefficient

0.13

$-0.07$

$-0.08$

0.14

$-0.15$

0.84

0.01

0.47

$-0.19$

$-0.66$

67.57
$\mathrm{P}>|\mathrm{z}|$

0.50

0.68

0.54

0.20

0.41

0.00

0.96

0.00

0.13

0.00

0.00

Source: Inwood, K, Oxley, L. and Roberts, E. (2009) "Rather above than under the common size? Stature and Living Standards in New Zealand", unpublished paper presented to the World Economic History Congress, Utrecht 